This PDF is a selection from an out-of-print volume from the National Bureau of Economic Research

Volume Title: NBER Macroeconomics Annual 1988, Volume 3

Volume Author/Editor: Stanley Fischer, editor

Volume Publisher: MIT Press

Volume ISBN: 0-262-06119-8

Volume URL: http://www.nber.org/books/fisc88-1

Publication Date: 1988

Chapter Title: What are the Costs of Excessive Deficits?

Chapter Author: David Romer

Chapter URL: http://www.nber.org/chapters/c10952

Chapter pages in book: (p. 63 - 110) 


\section{David Romer}

PRINCETON UNIVERSITY AND NBER

\section{What Are the Costs of Excessive} Deficits?

\section{Introduction}

United States federal government budget deficits have been exceptionally large in the 1980's. Figure 1, for example, shows the change in the real stock of government debt since 1950; the contrast between the periods before and after 1982 is obvious. ${ }^{1}$ Opinions concerning the welfare consequences of these deficits differ wildly. At one extreme is the supply-side view that "deficits that result from reducing ... marginal tax rates" are highly desirable because they "strengthen people's claims to the income produced by their work effort and their human, financial, and physical capital" (Roberts, 1984, p. 310). The other extreme is represented by the position that large deficits represent "a prescription for economic stagnation with no end in sight" that will cause the economy to "remain locked into a depressed and unstable condition" (Blumenthal et al., 1983). Between these two extremes lie a variety of positions, including the view that the deficits are desirable because they create political pressure to reduce government spending and the view of Robert Barro and others that the deficits are relatively unimportant. ${ }^{2}$

None of these claims about the effects of deficits is based on a formal analysis of deficits' welfare consequences; judgments of deficits' desirability, whether by economists or by others, are generally either entirely informal or based on a combination of formal analyses of deficits' positive

1. Typical forecasts call for the rate of increase in real debt to diminish only gradually (see for example U.S. Congressional Budget Office, 1987). Not surprisingly, conventional equations for the change in government debt that are estimated over the pre-1982 period dramatically underpredict the recent increases (Poterba and Summers, 1987).

2. For the former position, see the view attributed to David Stockman by Daniel Patrick Moynihan (New York Times, July 11, 1985, p. A14); for the latter, see Barro (1984). 
effects (the extent of crowding out, for example) and informal assessments of the welfare implications of those effects. Yet-as the divergence of opinion suggests - determining the welfare effects of deficits is extremely difficult. And the task remains difficult even when there is agreement on the channels through which deficits affect the economy; simply comparing steady states, for example, is often quite misleading.

But assessing quantitatively the various costs and benefits of deficits is essential in determining appropriate policy. Deficits can potentially affect the economy through many different channels, and each effect is likely to have welfare implications. Thus, if we are to have any hope of obtaining a clear picture of what course fiscal policy should follow, we must have some understanding of the direction and size of these welfare costs.

This paper is intended to be a preliminary step toward obtaining quantitative estimates of the costs and benefits of deficits. Because there are simple conditions under which deficits are irrelevant (Barro, 1974), and because there are many possible reasons that debt irrelevance might fail and no consensus on which reasons are most likely to be important in practice, no definitive assessment of the welfare effects of deficits is currently even remotely possible. I consider, therefore, several possible sources of real effects of deficits. And since recent discussion of deficits has focused mainly on the possibility that large deficits might be undesirable, I

Figure 1 CHANGE IN REAL FEDERAL DEBT OUTSTANDING, 1950-86 (\% OF GNP)

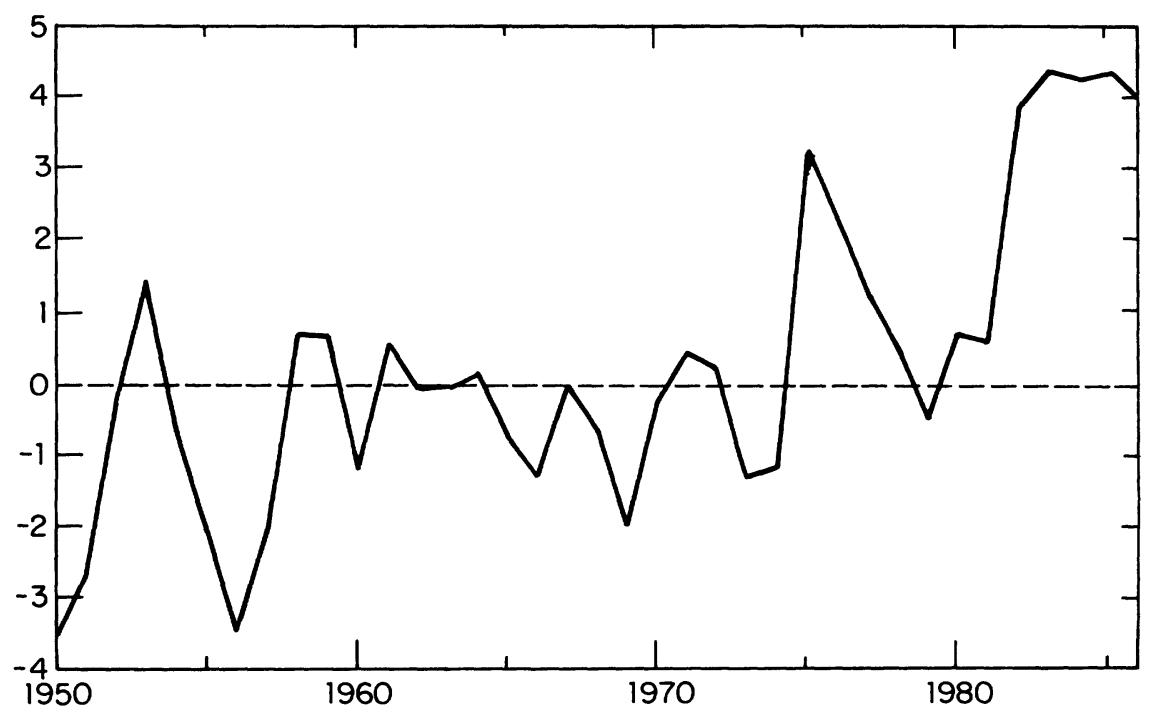


concentrate on possible costs rather than possible benefits of deficits. In particular, I consider a series of models in which deficits matter and analyze in each the welfare costs of a period of temporarily high deficits. Since my goal is to obtain quantitative estimates - albeit rough ones—of the costs, I make considerable use of numerical solutions to the models. Even so, the models are necessarily highly stylized; the cost estimates are not intended to be precise, but rather to suggest whether (and under what conditions) the costs of policy mistakes are likely to be large or small.

I consider three distinct channels through which deficits could be undesirable. These channels are analyzed in Sections 2, 3 and 4. In the concluding section I briefly discuss other possible channels through which deficits might produce large welfare costs.

The first channel that I consider is probably the most traditional: a tax cut has real effects because part of the burden of repaying the government debt falls on individuals who have not yet been born at the time the tax cut is made. In this case, deficits help current generations at the expense of future ones both through their direct distributional effects and through raising consumption, reducing capital formation, and thus increasing real interest rates and lowering wages.

The second channel that I explore may correspond most closely to popular perceptions of the costs of deficits. I assume that deficits have large contemporaneous effects on consumption because of liquidity constraints. (In contrast, if deficits have real consequences only because of intergenerational effects, then tax cuts have only small effects on consumption for plausible parameter values.) Intergenerational considerations are assumed to be negligible. The reductions in capital that result from the increase in consumption are undesirable because, following P. Romer (1987), there are assumed to be positive externalities to capital in production. (In the absence of such an externality or some other market failure, a tax cut, by relaxing liquidity constraints, increases welfare.) In short, large deficits cause a "spending binge" that leads to an "inadequate capital stock."

The final channel is the most straightforward: temporarily low taxes in the present imply that taxes must be higher in the future and thus that the pattern of taxes is not smooth. This in turn implies-assuming that taxes are distortionary and that higher taxes cause greater distortions per unit of revenue raised-unnecessarily large distortions. This is the mechanism explored by Barro (1979). ${ }^{3}$

3. Throughout I neglect any possible cyclical effects of deficits. Given the periods of time that I consider (several years at a minimum), a full employment model seems appropriate. Moreover, monetary policy could be used to offset any short-run effects of deficits on output via aggregate demand. 
The paper's most striking conclusion emerges from the model of Section 2 , in which a policy of low current taxes followed by higher taxes in the future has distributional effects across generations. I find that for reasonable parameter values the welfare costs of excessive deficits are likely to be large, and moreover, that this is the case even if the effects of the policy on consumption, capital formation, and the real interest rate are negligible. In fact, I show that the costs of deficits through their distributional effects are to a first approximation unaffected by the strength of the links between present and future consumers (as long as the links are not perfect). As the links between generations increase, the size of the redistribution caused by a given policy falls, but the welfare cost per unit of redistribution rises; the two forces approximately balance. Thus, it is possible-indeed plausiblefor deficits to have large costs even if their distributional effects and their effects on consumption are small.

It is essential to these results that the capital stock initially be too low. In the presence of overlapping generations, the equilibrium capital stock need not be optimal. More importantly, it is widely believed that the capital stock is in fact too low; for example, every Economic Report of the President during the past decade has argued that the capital stock needs to be increased. I show that if the real interest rate is too high, redistributions from future to current generations have first order welfare costs independently of whether or not there are any effects on capital accumulation. It is the impact of the direct distributional effects of deficits on social welfare that leads to the result that deficits can be costly even if their effects on consumption are trivial. The costs involved can be quite large. If the gap between the actual and optimal rates of return is roughly four percentage points (a typical estimate; see Feldstein, 1977, for example), the cost of a temporary tax cut of 4 percent of GNP for ten years followed by a policy of permanently rolling over the additional debt created by the tax cut is likely to be in the range of one to two trillion dollars - equivalent to the loss of approximately half of a year's consumption, or, to put it differently, equivalent to the loss of resources that are approximately equal in value to the total amount of the tax cut.

The model of Section 3, in which temporary deficits decrease capital formation because of liquidity constraints and in which capital formation has positive externalities, also implies that the costs of excessive deficits can be very large. Again, it is possible to construct examples using not unreasonable parameter values in which the costs of temporary deficits of 4 percent of GNP for ten years are over a trillion dollars. The implications of the model of Section 3 are less clear than those of Section 2, however, for two reasons. First, here the size of the costs depends critically on the 
magnitude of deficits' impact on consumption; since this magnitude is highly uncertain, the costs of deficits cannot be estimated with any confidence. Second, in this model deficits have not only a cost (the negative externalities from reduced investment), but also a benefit (the relaxation of liquidity constraints). Little is known about the magnitude of either effect. Thus, while it is possible to construct examples in which the costs of deficits are large, more natural choices of parameter values suggest considerably smaller costs, and there are sets of parameter values that are not obviously unreasonable that imply substantial benefits to deficits.

Finally, the tax smoothing model suggests costs of excessive deficits that are substantially smaller than those that can be obtained from the first two models, but that are nonetheless not negligible. For a typical set of parameter values, the cost of running a deficit of 4 percent of GNP for 10 years is about 50 billion dollars-about 2 percent of a year's consumption.

In all three models, the costs of an excessively large deficit rise approximately linearly with the length of time that the deficit is allowed to persist. Moreover, in the first model (but not in the other two) the costs can be reduced considerably by retiring the new debt at a moderate rate once the period of high deficits is ended. Thus, the results support the view that the costs of excessive deficits are steady and cumulative, as opposed to the view that excessive deficits for a few years are relatively harmless but that the costs rise rapidly as the period that the problem remains uncorrected lengthens.

What, in the end, can one conclude from this analysis concerning current U.S. fiscal policy? If one is not willing to take a stand on the underlying assumptions of the various models considered in this paper, then at this point little can be said about the costs of the current deficits. There are reasons that the deficit might have large costs, reasons that its welfare effects might be small, and even reasons that it might have substantial benefits. If, on the other hand, one accepts the propositions that present and future consumers are less than perfectly linked and that the capital stock is too low, then the analysis of this paper implies that there is a channel through which the deficit has large costs. Thus any case for the deficit, whether economic or political, must rest on an argument that there are large offsetting benefits. In the absence of such benefits, the deficit is very harmful and its harms are growing steadily. 


\section{The Burden on Future Generations}

\subsection{FRAMEWORK}

In this section I investigate the costs of excessive deficits, assuming that deficits affect social welfare by transferring wealth from future to current generations. A policy of lower taxes today and higher taxes in the future reduces the present value of taxes paid by those currently living and increases the value of taxes paid by those born in the future; in addition, it reduces the capital stock and thereby increases interest rates and decreases wages, again helping current generations at the expense of future ones. Because this type of policy has distributional effects, Pareto rankings of alternative policies are generally not possible. But if one is willing to make judgments about our relative valuations of the welfares of different individuals (as is done, for example, in standard analyses of the "Modified Golden Rule"), one can determine the effects of policy changes on social welfare.

The particular model that I use in this section follows Blanchard (1985) and Weil $(1987 \mathrm{a}, \mathrm{b})$. The model is set in continuous time. There is a continual arrival of new agents; $n e^{n t}$ agents are born at time $t$. Following Blanchard, all agents living at any time have the same expected remaining length of life; thus I abstract from life cycle effects. ${ }^{4}$ In fact, I adopt the stronger assumption, due to Weil, that agents never leave the economy; that is, agents have infinite horizons. As described below, assuming finite horizons does not change the central results. Thus, the magnitude of intergenerational effects depends simply on the rate of population growth $n$. Because the model is presented by Weil, I simply sketch it here.

2.1.1 Individual Behavior. Consider an agent born at time $d$. The agent has constant elasticity of substitution utility:

$U=\int_{t=d}^{\infty} e^{-\alpha(t-d)} \frac{\hat{C}(t ; d)^{1-\theta}}{1-\theta} d t, \quad \delta \geq 0, \quad \theta>0$

4. The obvious alternative would be to assume that all agents have some fixed lifespan, and thus that remaining length of life declines one-for-one with age. In fact, because expected years until death decrease less than one-for-one with age, the truth is somewhere between the two cases. I assume a constant remaining length of life because it is much simpler. Auerbach and Kotlikoff (1987) analyze the consequences of a variety of fiscal policy changes in a model of fixed lifetimes. 
$\delta$ is the discount rate, $\theta$ the coefficient of relative risk aversion (the inverse of the elasticity of intertemporal substitution), and $\hat{C}(t ; d)$ consumption at time $t$ of an agent born at $d$.

The agent supplies one unit of labor inelastically. I allow for the possibility of labor-augmenting technological progress at rate $g$, so the number of units of "effective labor" the individual supplies at $t$ is $e^{g t}$. Let $w(t)$ be the wage per efficiency unit of labor, $T(t)$ the level of (lump-sum) taxes per efficiency unit, and $C(t ; d)$ consumption per efficiency unit (thus $\left.C(t ; d)=\hat{C}(t ; d) / e^{g t}\right)$. In addition let $r(t)$ be the instantaneous real interest rate at $t$, and let $\tilde{r}(t)=r(t)-g$. Thus we can rewrite lifetime utility as

$U=e^{(1-\theta) g d} \int_{t=d}^{\infty} e^{-\tilde{\delta}(t-d)} \frac{C(t ; d)^{1-\theta}}{1-\theta} d t$,

where $\tilde{\delta}=\delta-(1-\theta) g$. The individual's lifetime budget constraint is $\int_{t=d}^{\infty} C(t ; d) e^{-\tilde{R}(d, t)} d t=\int_{t=d}^{\infty}[w(t)-T(t)] e^{-\tilde{R}(d, t)} d t$,

where $\tilde{R}\left(t_{1}, t_{2}\right)=\int_{q=t_{1}}^{t_{2}} \tilde{r}(q) d q$.

The solution to the individual's lifetime utility-maximization problem is described by Blanchard and Weil. Several facts about the utility-maximizing consumption program in a steady state are noted here for future reference. The marginal propensity to consume out of wealth is constant both over time and across individuals of different ages at the same time; it is given by $\tilde{r}-[(\tilde{r}-\tilde{\delta}) / \theta] \equiv c$. At time $t$, the wealth of an individual born at $d$ (per unit of effective labor) is

$e^{(\tilde{r}-\tilde{\delta})(t-d) / \theta}\left[\frac{w-T}{\tilde{r}}\right]$.

The level of utility that an individual born at date $d$ who has wealth $W$ per unit of effective labor at age $a$ can attain over the rest of his life (discounted back to the time of his birth) is

$U(W, a, d)=e^{(1-\theta) g d} e^{-\tilde{\delta} a} C^{-\theta} \frac{W^{1-\theta}}{1-\theta}$.

From (2.3) and (2.4), the marginal utility of wealth is 
$\frac{\partial U}{\partial W}=c^{-\theta} e^{-\tilde{r} a} e^{(1-\theta) \mathrm{gd}}\left[\frac{w-T}{\tilde{r}}\right]^{-\theta}$.

2.1.2 Aggregate Behavior. Wealth equals financial plus human wealth (i.e., discounted future labor income),

$W(t)=W_{F}(t)+W_{H}(t)$

and financial wealth in turn consists of bonds and capital,

$W_{F}(t)=B(t)+K(t)$.

Bonds and capital are perfect substitutes.

Financial wealth evolves according to

$\dot{W}_{F}(t)=(\tilde{r}(t)-n) W_{F}(t)+[w(t)-T(t)]-C(t) ;$

the first term reflects interest income and population growth, the second labor income, and the third spending. The change in human wealth is given by

$\dot{W}_{H}(t)=\tilde{r}(t) W_{H}(t)-[w(t)-T(t)] ;$

$\tilde{r}(t)$ appears rather than $\tilde{r}(t)-n$ because new individuals have human wealth.

2.1.3 Government. For convenience, government spending is assumed to be zero. The dynamics of the stock of government bonds (per unit of effective labor) are given by

$\dot{B}(t)=(\tilde{r}(t)-n) B(t)-T(t)$.

2.1.4 Production and Capital. Output net of depreciation is given by a conventional constant return to scale production function of capital and effective labor. Output per unit of effective labor is thus given by

$Y(t)=f(K(t))$

$f^{\prime}(\cdot)>0, f^{\prime \prime}(\cdot) \leqslant 0$. Investment is output minus consumption:

$\dot{K}(t)=f(K(t))-C(t)-(n+g) K(t)$. 
Finally, factors are paid their marginal products:

$r(t)=f^{\prime}(K(t)), \quad(2.13)$

$w(t)=f(K(t))-r(t) K(t)$.

It is straightforward to extend the model to allow for the possibility of some domestic assets being owned by foreigners (or foreign assets being owned domestically). Specifically, if it is assumed that net foreign holdings of domestic assets (per unit of effective labor) can be written simply as a function of $r, A^{F}(t)=A^{F}(r(t))$, then the model holds essentially as before. ${ }^{5}$ $A^{F^{\prime}}(\cdot)=\infty$ would correspond to the case of a small open economy that must take the world interest rate as given; $A^{F^{\prime}}(\cdot)=0$ would correspond to an economy that is, at the margin, closed.

2.1.5 Social Welfare Function. The social welfare function that I use to weight changes in the utilities of different individuals is the usual one. Let $U_{0}(d)$ be the lifetime utility of an individual born at $d$. Then the measure of social welfare is

$$
S W=\int_{d=-\infty}^{\infty} e^{-\beta d} n e^{n d} U_{0}(d) d d
$$

$\beta$ is the rate at which the utility of future individuals is discounted. A case that may be of special interest is $\beta=0$, which means that individuals are weighted equally regardless of their date of birth. For example, (2.15) with $\beta=0$ is the social welfare function that agents would agree on as the appropriate one for policy choices if they could somehow select the social welfare function before knowing their dates of birth. ${ }^{6}$

5. If $A(t)$ denotes financial assets held domestically, (2.7) becomes $A(t)+A^{F}(r(t))=B(t)+K(t)$. In addition, (2.12) must be modified to account for the fact that $r(t) A^{F}(r(t))$ of output accrues to foreign asset holders and for changes in foreign holdings, $\dot{A}^{F}(t)=A^{F^{\prime}}(r(t)) f^{\prime \prime}(K(t)) \dot{K}(t)$.

6 . The standard way of writing social welfare is as a function of the utilities of representative members of each generation:

$S W=\int_{d=-\infty}^{\infty} e^{-\dot{\beta} d} U_{0}(d) d d$.

This formulation is obviously equivalent to (2.15) with $\tilde{\beta}=\beta-n$. I adopt the formulation in (2.15) on the grounds that it is more natural to think of individuals, rather than generations, as the fundamental objects of concern. 
Alternatively, focusing on social welfare from time 0 forward, social welfare can be written as

$$
S W=\int_{a=0}^{\infty} e^{\beta a} n e^{-n a} V(a) d a+\int_{d=0}^{\infty} e^{-\beta d} n e^{n d} U_{0}(d) d d,
$$

where $V(a)$ denotes the utility from time 0 forward, discounted back to the date of birth, of an agent of age $a$ at time 0 . The first term of $\left(2.15^{\prime}\right)$ reflects the utilities of those alive at time 0 and the second term the utilities of those born after $t=0.7$

One can show that the usual "Modified Golden Rule" (Phelps, 1966) holds in this model: if $\beta+\theta g$ is greater than or equal to the growth rate of the economy, $g+n$, the optimal steady state interest rate is $\beta+\theta g \equiv r^{*}$; if $\beta+\theta g<g+n$, on the other hand, no optimal policy exists. When $r$ is not equal to $r^{*}$, redistributions among agents of different ages affect social welfare. From (2.5), in steady state the marginal utility of wealth at time $t$ for an agent born at $d$ is $e^{-\bar{r} t} e^{(r-\theta g) d} c^{-\theta}((w-T) / \tilde{r})^{-\theta}$; the marginal effect on social welfare of wealth of this agent is thus $e^{-\tilde{r} t} e^{(r-\theta g-\beta) d} c^{-\theta}((w-T) / \tilde{r})^{-\theta}$. If $r>\beta+\theta g$ this expression is increasing in $d$-redistribution from older to younger agents increases the social welfare function. Intuitively, when $r$ is high, older agents have been able to save at a high rate of return for a considerable length of time, and thus have low marginal utilities of consumption.

\subsubsection{Policy Changes. In what follows I analyze the effects of temporary tax} cuts on social welfare. Starting in a steady state at time zero, for some interval $H$ taxes are low and the stock of government debt is rising; at time $H$ taxes are raised to the level needed to keep the debt constant. Specifically, the basic policy experiment that I consider is reducing taxes so that

7. As Calvo and Obstfeld (1987) discuss, failing to discount the utilities of those alive at time 0 back to their dates of birth would lead to time inconsistency. The integral in (2.15) often diverges. In fact, what I do below is to compare policies using the measure

$$
\Delta S W=\int_{d=-\infty}^{\infty} e^{-\beta d} n e^{\text {nd }}\left(U_{0}^{1}(d)-U_{0}^{0}(d)\right) d d
$$

where $U_{0}^{1}(d)$ and $U_{0}^{0}(d)$ are the lifetime utilities of an individual born at $d$ under the two policies being compared. See Phelps (1966) for a discussion of the appropriateness of this procedure despite the fact that (2.15) may diverge. 
the stock of debt, $B$, rises at some steady rate $\Delta T$ over the interval $(0, H)$, followed by a tax increase at $H$ to keep $B$ constant thereafter. Thus:

$\dot{B}(t)= \begin{cases}\Delta T & 0 \leq t<H \\ 0 & t \geq H .\end{cases}$

The implications of this policy for the path of taxes can be found using the government budget constraint (2.10):

$T(t)=(\tilde{r}(t)-n) B(t)-\dot{B}(t)= \begin{cases}T^{S S}-\Delta T+(\tilde{r}(t)-n) t \Delta T & 0 \leq t<H \\ T^{S S}+(\tilde{r}(t)-n) H \Delta T & t \geq H,\end{cases}$

where "ss" denotes a steady state value.

Under (2.16)-(2.17), taxes are adjusted during the period of the tax cut to pay the interest on the additional debt, and so the stock of debt grows linearly, rather than exponentially. I focus on this case because recent policy has not involved steadily growing deficits. Below I briefly discuss the effects of not adjusting taxes during the period of the tax cut.

I also consider the implications of gradually retiring the additional debt created by the tax cut, rather than maintaining the stock of debt at its higher level after $H$. Specifically, I consider policies of form:

$\dot{B}(t)= \begin{cases}\Delta T & 0 \leq t<H \\ -\alpha e^{-\alpha(t-H)} H \Delta T & t \geq H .\end{cases}$

If $\alpha>0, B(t)$ returns asymptotically to its initial level.

\subsection{CONSTANT REAL INTEREST RATE}

In this section I assume that the real interest rate is fixed. This corresponds either to the case of an economy that is at the margin completely open, or, less plausibly, to the case of perfect substitutability between capital and labor. This assumption has two advantages. First, it permits considerable progress to be made analytically. Second, since it implies that future wages are unaffected by current policy, it allows me to focus on the direct distributional effects of deficits. Moreover, given the extent of capital mobility, it is probably only moderately unrealistic.

2.2.1 General Results. The first step in finding the effect of the policy on social welfare is to compute its impact on the wealth of various generations. Define 


$$
\Delta W(t)=\int_{s=t}^{\infty} e^{-\tilde{r}(s-t)}\left[T^{S S}-T(s)\right] d s, \quad t \geq 0 .
$$

For an individual born at date $d \geqslant 0, \Delta W(d)$ is the effect of the policy on his lifetime wealth. In addition, $\Delta W(0)$ is the effect on the wealth as of time 0 of individuals living at zero. $\Delta W(t)$ can be found by substituting (2.17) into (2.19). The effect of the policy on social welfare can then be found using (2.3) and (2.4):

$$
\begin{aligned}
\Delta S W=\int_{a=0}^{\infty} e^{\beta a} n e^{-n a}[ & U\left(e^{(\tilde{r}-\tilde{\delta}) a / \theta} \bar{W}_{0}+\Delta W(0), a,-a\right) \\
& \left.-U\left(e^{(\tilde{r}-\bar{\delta}) a / \theta} \bar{W}_{0}, a,-a\right)\right] d a \\
+ & \int_{t=0}^{\infty} e^{-\beta t} n e^{n t}\left[U\left(\bar{W}_{0}+\Delta W(t), 0, t\right)-U\left(\bar{W}_{0}, 0, t\right)\right] d t
\end{aligned}
$$

where $\bar{W}_{0}=\left(w-T^{s s}\right) / \tilde{r}$ and where $U(W, a, d)$, given in (2.4), is the utility from age $a$ forward (discounted to the date of birth) of an individual born at $d$ with wealth $W$ at age $a$. The first term of (2.20) gives the effect of the policy on the welfare of those living at the time the policy is announced, and the second term shows the impact on those born after $t=0$.

To convert (2.20) into understandable units, I define $\chi$ to be the marginal effect on social welfare of an increase in all individuals' consumption at $t=0$. From (2.5) and (2.15),

$$
\begin{aligned}
X & =\int_{a=0}^{\infty} e^{\beta a} n e^{-n a} c^{-\theta} \bar{W}_{0}^{-\theta} e^{-\tilde{r} a} e^{-(1-\theta) g a} d a \\
& =\frac{n c^{-\theta} \bar{W}_{0}^{-\theta}}{n+\tilde{r}+(1-\theta) g-\beta}
\end{aligned}
$$

In what follows I focus on the measure

$$
L=\frac{-\Delta S W}{\chi C(0)},
$$

where $C(0)$ is aggregate consumption at time 0 . Thus, I normalize the change in social welfare by the "marginal social utility of consumption" times the initial level of consumption. For example, a value of $L$ of .5 would 
mean, if time is measured in years, that the social welfare cost of the temporary increase in deficit spending was equivalent (loosely speaking) to losing half a year's consumption.

2.2.2 First Order Approximations. Because lifetime wealth is large, the impact of even a fairly substantial tax cut on individuals' wealths is generally small. In this case the change in an individual's utility can be well approximated by his marginal utility of wealth times the change in his wealth.

To interpret the welfare costs of tax cuts, it is useful to begin by considering a temporary (i.e., momentary) tax cut of amount $\Delta T$ at $t=0$ that is repaid $H$ periods later, where $H$ is small. Each of the $n H$ people born during $(0, H)$ loses $\Delta T$; each person alive at $t=0$ gains $n H \Delta T$ dollars. Thus the amount transferred is proportional to $n$. If $r$ exceeds $r^{*}$, transfers from younger to older individuals are undesirable. The larger the difference in age, the more undesirable the transfer. Here the transfer is from individuals born at approximately $t=0$ to individuals alive at $t=0$. But the average age of individuals alive at $t=0$ is decreasing in $n$; specifically, it is $1 / n$. Thus, when $r>r^{*}$, the ratio of the marginal social values of a unit of wealth to the newborn and of a unit of wealth to those alive is decreasing in $n$; one can show that it is $1+\left(r-r^{*}\right) / n$. Thus, although the size of the transfer is falling in $n$, the social welfare cost per unit is rising. The overall welfare effect of the policy change is (approximately)

$L \cong\left(r-r^{*}\right) H \frac{\Delta T}{C(0)}$.

The two effects balance, and so the size of a deficit's impact on consumption, to a first approximation, is not relevant to its welfare cost.

The welfare effects of a tax cut over $(0, H)$ with the additional debt permanently rolled over after $H$ differ from those of a momentary cut at $t=0$ that is fully repaid at $H$ for two reasons. First, because the future tax increase to balance the present cut is spread out rather than concentrated at $H$, more of the burden of paying for the tax cut falls on future generations. Second, with the policy of a permanently higher debt the transfer to those who are living at 0 is from all future generations, rather than from those born during $(0, H)$; with $r>r^{*}$, this is less desirable. Equation (2.5) giving the marginal utility of wealth, equation (2.19) giving the changes in individuals' wealths, and equation (2.15) giving social welfare, together with the additional assumption that $H$ is small, can be used to derive an approximation to the effect of the tax cut on social welfare. The resulting expression is 
$L \cong \frac{r-r^{*}}{r^{*}-(n+g)} H \frac{\Delta T}{C(0)}$.

Because the policy of a tax cut over $(0, H)$ followed by a permanently higher stock of debt after $H$ (with permanently higher taxes to pay the additional interest) involves reducing the wealths of all future generations, and because $r>r^{*}$ implies that the marginal effect on social welfare of a given transfer (in present value terms) rises as we consider generations further in the future, (2.24) can be quite large. Recall that the condition for an optimal policy to exist is $r^{*} \geqslant n+g$. As $r^{*}-(n+g)$ approaches zero, (2.24) diverges. For example, $H=15, \Delta T / C(0)=0.6, r-r^{*}=0.4, \beta=0$, $n=.01, g=.02$, and $\theta=3$ imply $L \cong 1$.2. The same parameter values with $\theta=1.5$ imply that $L$ diverges.

Because the large welfare costs stem to a considerable extent from the effects of the policies on generations in the distant future, even very gradual retirement of the debt can substantially lower $L$. Equation (2.18) describes policies where the debt created by the tax cut is retired at some rate $\alpha$ after time $H$. One can show that for general $\alpha$ the formula analogous to $(2.24)$ is

$L \cong \frac{r-r^{*}}{\alpha+r^{*}-(n+g)} H \frac{\Delta T}{C(0)}$.

For the same parameter values as before (with $\theta=3$ ), raising $\alpha$ from 0 to .014 (so that half the debt is retired in 50 years) lowers $L$ from 1.2 to .8 ; $\alpha=.035$ (half is retired in 20 years) lowers $L$ to .6. For $\theta=1.5, L$ is 2.6 for $\alpha=.014$ (50 years), 1.0 for $\alpha=.035$ (20 years), and .5 for $\alpha=.069$ (10 years). In the case of both world wars, more than half of the wartime increase in the ratio of federal debt to GNP had been reversed within ten years after the end of the war. Thus, a half-life of as little as ten years does not appear unreasonable. ${ }^{8}$

It is important to note that because the source of the welfare effects is transfers among generations, introducing factors that would cause tax cuts to have a larger impact on consumption would not significantly affect the welfare costs. For example, if we simply make the arbitrary assumption

8. (2.24') implies that the costs are minimized when $\alpha$ is set to infinity-that is, when the debt is retired immediately by a large onetime levy at $H$. Considerations outside the scope of the model, such as the fact that taxes are not lump sum and the fact that taxes may affect output through aggregate demand, suggest that such a policy is unrealistic. Thus, although I discuss the $\alpha=\infty$ case briefly below, I do not focus on this case. (Also, as described below, the approximation in (2.24') is unreliable when $\alpha$ is large.) 
that individuals consume their disposable labor income, (2.24) and (2.24') are unchanged. Thus, if the source of welfare costs of temporary tax cuts is transfers among generations and if $r$ is fixed, then to first order large effects of current income on consumption do not alter the welfare costs.

Finally, assuming that lifetimes are finite rather than infinite also does not change the results. Specifically, following Blanchard, suppose that death is a Poisson process with arrival rate $p$; that is, the probability of an individual alive at $t$ living to $t^{\prime}$ is $e^{-p\left(t^{\prime}-t\right)}$. Suppose also that individuals hold all wealth as annuities. Then the central results are unchanged: the optimal interest rate is $r^{*}=\beta+\theta g$, and formulas (2.24) and (2.24') hold as before (where $n$ continues to denote the rate of population growth). Thus the assumption of infinite horizons is unimportant to the results.

\subsubsection{Exact Results. To find the effect of excessive deficits on social welfare} in this model without using Taylor approximations, the integral giving $\Delta S W$-equation (2.20)-must be evaluated numerically. I focus throughout on the case of $\Delta T / C(0)=0.06$-taxes are cut by 6 percent of initial consumption. (For the United States this corresponds to a tax cut of approximately 4 percent of GNP.) As baseline values of the other parameters, I set the coefficient of relative risk aversion $(\theta)$ to 3 , the rate of labor-augmenting technological progress $(g)$ to 2 percent, the rate of arrival of new agents $(n)$ to 1 percent, the social planner's discount rate $(\beta)$ to zero, and the marginal product of capital net of depreciation $(r)$ to 10 percent. I choose $T$ so that the initial debt-to-GNP ratio is .4. Finally, I choose $\delta$ so that the steady state capital-output ratio is 2.5; the implied value is approximately 3 percent. I consider five possible values for the length of time that taxes are reduced: $1,5,10,15$, and 20 . In addition to finding $L$ for the baseline case, I also consider the effects of varying $\theta, g, n, \beta$, and $r$. For each set of parameter values I adjust $\delta$ so that the initial capital-output ratio remains equal to 2.5; the implied values of $\delta$ range from .3 percent to 6.2 percent.

Tables $1-4$ report the results. In Table 1 (in which it is assumed that the debt is permanently rolled over after the end of the tax cut), the first order approximation derived above $-L \cong\left[\left(r-r^{*}\right) /\left(r^{*}-n-g\right)\right] H[\Delta \mathrm{T} / C(0)]-$ provides a relatively good guide to the exact results. When the additional debt is gradually retired after the end of the tax cut (Table 2), the approximation in (2.24') provides a good measure of the actual costs of the policy for all of the cases considered, except instantaneous retirement at time $H(\alpha=\infty)$. For $\alpha=\infty$, temporary deficits have potentially large costs even though $\left(2.24^{\prime}\right)$ implies $L \cong 0$. One can show that including the second order terms in $H$ in the approximation implies that for the case of $\alpha=\infty$, 
$L \cong 1 / 2\left(r-r^{*}\right) H^{2}[\Delta T / C(0)]$ (see (2.23)); thus, with immediate repayment the costs of excessive deficits increase with the square of the deficits' duration.

Table 3 shows that for sets of parameter values that imply that the initial steady state is optimal (and thus the costs of deficits are second order), the welfare costs of deficits are generally small. Finally, Table 4 considers the effects of not adjusting taxes over $(0, H)$ to pay the interest on the debt created by the tax cut. Thus, in this case $T(t)$ is simply $T^{s s}-\Delta T$ for $0<t<H$ and $T^{s s}+\left(e^{\tilde{r} H}-1\right) \Delta T$ for $t \geqslant H$. Under this policy the stock of government debt grows exponentially rather than linearly during the period $(0, H)$. Table 4 shows, not surprisingly, that the effect of this change is small if $H$ is small, but can be substantial if $H$ is large.

The approximations in equations $(2.24)-\left(2.24^{\prime}\right)$ and the exact results presented in Tables $1-4$ show that if $r$ differs substantially from $r^{*}$, the

Table 1 THE COSTS OF EXCESSIVE DEFICITS

\begin{tabular}{|c|c|c|c|c|c|c|c|c|c|c|c|}
\hline \multicolumn{6}{|c|}{ Parameter Values } & \multirow[b]{2}{*}{$r-r^{*}(\%)$} & \multicolumn{5}{|c|}{$H$} \\
\hline$\beta(\%)$ & $g(\%)$ & $n(\%)$ & $r(\%)$ & $\theta$ & $\delta(\%)$ & & 1 & 5 & 10 & 15 & 20 \\
\hline \multicolumn{12}{|c|}{ Baseline Case } \\
\hline 0 & 2 & 1 & 10 & 3 & 3.3 & 4 & .080 & .388 & .753 & 1.097 & 1.421 \\
\hline \multicolumn{12}{|c|}{ Effects of Varying $\theta$} \\
\hline 0 & 2 & 1 & 10 & 2 & 5.5 & 6 & .360 & 1.805 & 3.621 & 5.450 & 7.296 \\
\hline 0 & 2 & 1 & 10 & 4 & 1.0 & 2 & .024 & .114 & .216 & .306 & .387 \\
\hline \multicolumn{12}{|c|}{ Effects of Varying $r$} \\
\hline 0 & 2 & 1 & 7 & 3 & 0.5 & 1 & .020 & .096 & .184 & .266 & .340 \\
\hline 0 & 2 & 1 & 15 & 3 & 7.8 & 9 & .180 & .914 & 1.862 & 2.855 & 3.911 \\
\hline \multicolumn{12}{|c|}{ Effects of Varying $n$} \\
\hline 0 & 2 & .1 & 10 & 3 & 3.9 & 4 & .061 & .292 & .559 & .800 & 1.021 \\
\hline 0 & 2 & 2 & 10 & 3 & 2.5 & 4 & .120 & .593 & 1.172 & 1.736 & 2.287 \\
\hline 2 & 2 & 5 & 10 & 3 & 0.4 & 2 & .120 & .600 & 1.195 & 1.784 & 2.364 \\
\hline \multicolumn{12}{|c|}{ Effects of Varying $g$} \\
\hline 0 & 1 & 1 & 10 & 3 & 6.2 & 7 & .422 & 2.151 & 4.411 & 6.792 & 9.311 \\
\hline 0 & 3 & 1 & 10 & 3 & 0.3 & 1 & .012 & .056 & .105 & .148 & .184 \\
\hline \multicolumn{12}{|c|}{ Effects of Varying $\beta$} \\
\hline 1 & 2 & 1 & 10 & 3 & 3.3 & 3 & .044 & .214 & .406 & .578 & .734 \\
\hline 3 & 2 & 1 & 10 & 3 & 3.3 & 1 & .010 & .046 & .086 & .119 & .146 \\
\hline
\end{tabular}

Note: $\Delta T=.06 C(0)$. The numbers reported are values of $L$. 


\section{Table 2 THE EFFECTS OF RETIRING THE DEBT}

Time after the end of the tax cut after which half the additional debt has been retired, in years

(implied value of $\alpha$ )

\begin{tabular}{rccccc} 
& $\infty$ & 50 & 20 & 10 & 0 \\
$H$ & $(0)$ & $(.0139)$ & $(.0347)$ & $(.0693)$ & $(\infty)$ \\
\hline 1 & .080 & .055 & .037 & .025 & .001 \\
5 & .388 & .272 & .193 & .135 & .028 \\
10 & .753 & .539 & .398 & .295 & .106 \\
15 & 1.097 & .802 & .611 & .474 & .224 \\
20 & 1.421 & 1.059 & .830 & .668 & .373 \\
\hline
\end{tabular}

See note to Table 1. Parameter values are $\beta=0, g=2 \%, n=1 \%, r=10 \%, \theta=3, \delta=3.3 \%\left(r-r^{*}=4 \%\right)$.

Table 3 THE COSTS OF EXCESSIVE DEFICITS $-r=r *$ CASE

\begin{tabular}{|c|c|c|c|c|c|c|c|c|c|c|}
\hline \multicolumn{6}{|c|}{ Parameter Values } & \multicolumn{5}{|c|}{$H$} \\
\hline$\beta(\%)$ & $g(\%)$ & $n(\%)$ & $r(\%)$ & $\theta$ & $\delta(\%)$ & 1 & 5 & 10 & 15 & 20 \\
\hline \multicolumn{11}{|c|}{ Baseline Case } \\
\hline 4 & 2 & 1 & 10 & 3 & 3.3 & .0001 & .001 & .004 & .008 & .012 \\
\hline \multicolumn{11}{|c|}{ Effects of Changes in Parameter Values } \\
\hline 4 & 2 & 1 & 12 & 4 & 2.8 & .0001 & .002 & .006 & .010 & .015 \\
\hline 4 & 2 & 2 & 10 & 3 & 2.5 & .0001 & .002 & .008 & .015 & .022 \\
\hline 4 & 1 & 1 & 7 & 3 & 3.5 & .0001 & .001 & .004 & .008 & .013 \\
\hline 2 & 2 & 1 & 8 & 3 & 1.4 & .0001 & .001 & .004 & .008 & .013 \\
\hline
\end{tabular}

See note to Table 1 .

Table 4 THE EFFECTS OF NOT ADJUSTING TAXES TO PAY THE INTEREST ON THE ADDITIONAL DEBT

\begin{tabular}{rcc}
\hline$H$ & Taxes Adjusted & $\begin{array}{c}\text { Taxes Not } \\
\text { Adjusted }\end{array}$ \\
\hline 1 & .080 & .082 \\
5 & .388 & .467 \\
10 & .753 & 1.116 \\
15 & 1.097 & 2.076 \\
20 & 1.421 & 3.644 \\
\hline
\end{tabular}

See note to Table 1. Parameter values are $\beta=0, g=2 \%, n=1 \%, r=10 \%, \theta=3, \delta=3.3 \%\left(r-r^{*}=4 \%\right)$. 
welfare costs of excessive deficits can be very large. The welfare costs of a tax cut of 6 percent of initial consumption lasting ten years with the debt permanently rolled over can easily reach a year's consumption for plausible parameter values. To put it differently, the cost of a tax cut of 180 billion dollars per year for ten years may exceed three trillion dollars. Gradual retirement of the debt after the tax cut is reversed can substantially reduce their welfare costs, but still leave them large. Retiring the debt with a halflife of ten years, for example, might cut the costs in half-from roughly a year's consumption to half a year's, or, stated differently, from roughly 3 trillion dollars to 1.5 trillion. While the character of this social cost of deficits is different from those that are usually emphasized (since it involves distribution, rather than efficiency), the results follow from a fairly widely held view - that the capital stock is too low-with quite modest additional assumptions.

Finally, the approximations and exact results suggest that the costs of excessive deficits mount steadily as the deficits persist. Equations (2.24)$\left(2.24^{\prime}\right)$, in fact, show that the costs are approximately linear in the horizon of the tax cut. Thus, there are no "crises" in the model, only steadily mounting costs. Indeed, the model implies that even after the tax cut is ended, its harms can be greatly mitigated by rapid repayment of the debt.

\subsection{ENDOGENOUS REAL INTEREST RATE}

I now briefly consider the implications of relaxing the assumption that the real interest rate is fixed. That is, I will assume that the increased consumption caused by a tax cut reduces investment and thereby increases the real interest rate and drives down the wage. This will occur (assuming that capital and labor are not perfect substitutes) either if capital is less than perfectly mobile, or if the economy is not negligible in comparison to the world; in the case of the United States, both conditions appear to hold.

If the real interest rate and the wage are not fixed, a temporary tax cut will affect social welfare not only through the direct distributional effects that are the focus of Section 2.2, but also through its effect on factor payments. Increased consumption raises the real interest rate and lowers the real wage, thereby helping suppliers of capital and harming suppliers of labor; since capital is held by those currently living, this effect, like the direct distributional effect, tends to benefit present generations at the expense of future ones.

When $r$ is endogenous, I am not able to solve analytically for the response of the economy to a change in fiscal policy. I therefore use numerical solutions throughout. I assume that production is Cobb-Douglas. I ignore international capital flows; increased consumption is translated one-for-one into reduced investment. Given actual capital mobility, my 
assumptions of Cobb-Douglas production and of no capital flows almost surely imply unrealistically large effects of increased consumption on factor payments. Thus, this model and the fixed real interest rate model should be viewed as extremes, with the truth almost certainly lying somewhere between the two.

I assume a capital share of one quarter; thus a capital-output ratio of 2.5 implies $r=10$ percent. I choose the remaining parameters as before: $\theta=3$, $g=2$ percent, $n=1$ percent, $\beta=0$, and $T$ and $\delta$ so that the initial bond-output and capital-output ratios are .4 and 2.5 .

For these parameter values the endogeneity of $r$ has only a modest effect on the welfare costs of deficits. For a tax cut of 6 percent of initial consumption for ten years, with the additional debt permanently rolled over thereafter, $L \cong .851$ when $r$ is endogenous and $L \cong .753$ when $r$ is fixed at 10 percent. This small effect is not surprising. The tax cuts affect consumption only because present and future consumers are not perfectly linked; since those links are strong, consumption changes only slightly. The long-run effect of the policy is to raise the real interest rate by 13 basis points and lower the real wage by $1 / 2$ percent.

When the links between generations are weaker the effects of tax cuts on consumption are greater, and thus the consequences of letting $r$ change as $K$ changes are also greater. Suppose, for example, that $n=4$ percent and $\beta=2$ percent and that the other parameters are as before. (I set $\beta>0$ so that $\beta+\theta g>n+g$.) For this case, $L$ is approximately .582 if $r$ is fixed and .947 if $r$ is endogenous. In the long run the policy raises $r$ by 53 basis points and lowers the wage by 1.7 percent.

Finally, I ask whether letting $r$ vary alters the welfare costs of tax cuts significantly when the economy begins in the optimal steady state. For $n=1$ percent, $\beta=4$ percent, and the other parameters as before (so that initially $\left.r=r^{*}\right), L \cong .006$ when $r$ is fixed and $L \cong .018$ when $r$ is endogenous. For $n=4$ percent and $\beta=4$ percent, $L$ is approximately .014 for $r$ exogenous and .063 for $r$ endogenous.

I conclude that allowing for the possibility of the increased consumption brought about by temporary tax cuts driving up the interest rate has only modest effects on the welfare costs of excessive deficits. Even if the arrival rate of new agents is 4 percent and production is Cobb-Douglas with no international capital flows - both of which almost surely overstate greatly the impact of deficits on the interest rate through imperfect links between present and future consumers - the welfare costs of deficits are not dramatically larger than they are when the interest rate is fixed. Thus, the central source of welfare costs of fiscal policy mistakes in this model is the direct distributional effect of those policies. As described in Section 2.2, those costs are likely to be substantial. 


\section{Liquidity Constraints}

\subsection{INTRODUCTION}

In traditional macroeconomic models and in many informal discussions of the effects of deficits, temporary tax cuts are assumed to have large contemporaneous effects on consumption. Although the results of formal econometric investigations of this issue are mixed, some studies provide support for this view. Campbell and Mankiw (1987), for example, conclude that the path of aggregate consumption behaves as though it were determined as roughly the average of permanent income and current income. In this section I investigate the costs of deficits in a model in which temporary tax cuts have large effects on consumption. Specifically, I assume that some consumers would like to consume more than their current income, but are unable to do the needed borrowing. By lowering taxes today and raising them in the future, the government in effect lends to private agents and thus relaxes the liquidity constraints that they face.

The interaction between liquidity constraints and government tax policy can be complex. Hayashi (1986) and Yotsuzuka (1987) show that there are natural models of endogenous liquidity constraints in which liquidity constraints respond to tax cuts in just such a way as to leave consumption unchanged. At the same time, this result is not general (see Bernheim, 1987, and Yotsuzuka). Because my goal is to develop a model that can be embedded in a larger model of the economy and that can be used to do quantitative welfare analysis, I do not attempt to build a model of endogenous liquidity constraints arising from, for example, adverse selection. Instead, I simply assume that for some reason-such as the existence of bankruptcy laws-lenders are unwilling to lend to individuals with zero financial wealth. The essential feature of this assumption is that the amount that individuals can borrow does not change in response to temporary tax cuts. The results that follow would be weakened but not changed qualitatively if liquidity constraints adjusted to weaken somewhat the stimulating effects of tax cuts on consumption.

In the absence of some offsetting cost, temporary tax cuts in a world of liquidity constraints are desirable. I assume, however, that the shifting of consumption from the future to the present that is caused by tax cuts does have a cost. Specifically, I assume that the social marginal product of capital exceeds the private marginal product, and thus that there is a negative externality to reduced saving. P. Romer (1987) defends the assumption of a positive externality to capital formation both theoretically and empirically 
and argues that the externality may be quite large. Finally, for simplicity I assume that the marginal product of capital is fixed. ${ }^{9110}$

\subsection{STEADY STATE}

The economy consists of two types of infinitely-lived agents; the two types of agents have the same labor incomes and taxes but different preferences and thus potentially different consumption paths and asset holdings. Let $r$ be the private real interest rate and $g$ the rate of technical progress, and define $\tilde{r}=r-g$. Let $w$ be the wage, $T$ taxes, $C_{i}$ the consumption of a type $i$ individual, and $A_{i}$ the financial wealth of a type $i$ individual; all variables are measured relative to the size of the economy (that is, divided by $e^{g t}$ ). Finally, let "ss" denote a steady state value.

An individual of type $i$ has the utility function

$U_{i}=\int_{t=0}^{\infty} e^{-\bar{\delta}_{i} t} \frac{C_{i}(t)^{1-\theta}}{1-\theta}, \quad \tilde{\delta}_{i} \geq 0, \theta>0 \quad(i=1,2)$.

9. The results of Section 2.3 suggest that with a small effect of deficits on consumption and extreme assumptions about how changes in consumption affect the interest rate, the welfare costs of deficits are only moderately larger than they are when the interest rate is fixed. It appears likely that the same would be true if deficits had a larger effect on consumption (as is likely to occur with liquidity constraints) and if more realistic assumptions were made about the impact of changes in consumption on the real interest rate. Thus, the assumption that $r$ is fixed, although not entirely innocuous, probably does not greatly affect the results. Note also that since tax cuts have an advantage when there are liquidity constraints, it appears that the net effect of adding liquidity constraints to the model of Section 2 would be to reduce the welfare costs of tax cuts.

10. If the mechanism by which tax cuts reduce welfare is negative externalities from increased consumption, the magnitude of tax cuts' effect on consumption is obviously crucial to the results. There are at least two possible means other than liquidity constraints through which temporary tax cuts could have large effects on consumption. The first is the interaction between uncertainty and the non-lump-sum nature of taxes stressed by Barsky, Mankiw, and Zeldes (1986). In a model integrating Barsky, Mankiw, and Zeldes's analysis with positive externalities from capital, tax cuts would again have an advantage and a disadvantage; in this case the advantage would be increased insurance against uncertainty in future income. It thus seems plausible that the welfare implications of tax cuts in such a model would be broadly similar to their implications in the present model. Because formal analysis of these issues would be quite complex, I do not pursue them further.

The second alternative means through which temporary tax cuts could have large effects on consumption is "irrational" or "rule of thumb" consumption behavior (see for example Johnson, Kotlikoff, and Samuelson, 1987). In an economy of rule of thumb consumers and externalities from capital, temporary tax cuts have a disadvantage without necessarily having an offsetting advantage (since the change in consumers' spending need not bring them closer to their privately optimal paths); thus the welfare costs of tax cuts are likely to be larger than in the present model. 
I assume that type 1 individuals have a higher discount rate than do type 2 individuals: $\tilde{\delta}_{1}>\tilde{\delta}_{2}$. It is type 1 individuals who will be liquidity constrained. Fraction $f$ of individuals are of type 1 .

The consumption that a type $i$ individual would choose if not liquidity constrained is

$$
\begin{aligned}
& \hat{C}_{i}^{s s}=c_{i}\left(\frac{w^{s s}-T^{s s}}{\tilde{r}}+A_{i}^{s s}\right), \\
& c_{i}=\tilde{r}-\frac{\tilde{r}-\tilde{\delta}_{i}}{\theta} .
\end{aligned}
$$

Type 1 individuals are liquidity constrained and type 2 individuals are not. Thus their actual consumptions are

$$
\begin{aligned}
& C_{1}^{s s}=w^{s s}-T^{s s}, \\
& C_{2}^{s s}=c_{2}\left(\frac{w^{s s}-T^{s s}}{\tilde{r}}+A_{2}^{s s}\right) .
\end{aligned}
$$

The condition for liquidity constraints to be binding for type 1 individuals only is $\tilde{\delta}_{1}>\tilde{r} \geqslant \tilde{\delta}_{2}$. In addition, steady state requires $\tilde{r}=\tilde{\delta}_{2}$. I therefore assume $\tilde{\delta}_{1}>\tilde{r}=\tilde{\delta}_{2}$. This implies $c_{2}=\tilde{r}$.

Since all financial wealth is held by type 2 individuals and since they represent proportion $1-f$ of the economy,

$$
(1-f) A_{2}^{s s}=B^{s s}+K^{s s},
$$

where $B$ and $K$ are the stocks of bonds and capital. In steady state, $B$ and $K$ must be constant:

$$
\begin{aligned}
& \dot{B}=\tilde{r} B^{s s}-T^{s s}=0, \\
& \dot{K}=Y^{s s}-\left(f C_{1}^{s s}+(1-f) C_{2}^{s s}\right)=0,
\end{aligned}
$$

where $Y$ is output less the investment needed to maintain $K(g K)$.

Let $w^{0}$ and $r^{0}$ denote the social marginal products of labor and capital. If $r^{0}$ exceeds $r$, there are positive externalities to capital. Thus output minus $g K$ is given by

$$
Y^{s s}=w^{0}+\tilde{r}^{0} K^{s s},
$$


where $\tilde{r}^{0}=r^{0}-g$. Finally, the wage equals output less payments to capital:

$w^{s s}=Y^{s s}-\tilde{r} K^{s s}$.

Equations (3.3)-(3.9) describe the steady state of the economy. The unknowns are $C_{1}, C_{2}, A_{2}, B, K, Y$, and $w$. One can show that because output is linear in capital and because $c_{2}=\tilde{r}$, any level of $K$ is a steady state value (as long as $B+K \geqslant 0$ ). As a result, temporary disturbances can permanently affect the capital stock. This makes the analysis of dynamics simpler. It appears that modifying the model so that there is a unique steady state to which the economy adjusts slowly would not substantially alter the results.

\subsection{POLICY CHANGES}

A liquidity constrained individual is at a corner solution; his marginal propensity to consume is one. Thus, if taxes are cut in a way that causes the path of taxes to be smooth and if the tax cuts are sufficiently small, type 1 (liquidity constrained) individuals will continue to always consume their current disposable income. Because the types of policy changes that we are interested in are of moderate size-several percent of GNP — and involve a path for taxes after the initial cut that is fairly steady, I focus on changes in tax policy that leave type 1 individuals' consumption at a corner solution.

A simple and tractable way of modeling such policy changes is to assume that taxes are initially cut by some amount and then rise exponentially to a new steady state level:

$$
T(t)=T^{s s}-A e^{-b t}+\frac{\tilde{r}}{\tilde{r}+b} A, \quad b>0, A>0 .
$$

The constant term is chosen so that the stock of government debt does not diverge. (Conditions on $A$ and $b$ and on the parameters of the model for it to be optimal for type 1 individuals to always consume their disposable income are discussed below.)

To gauge the magnitude and duration of tax cuts of form (3.10), note that (3.10) and $\dot{B}(t)=\tilde{r} B(t)-T(t)$ imply that $\dot{B}(t)=[b /(\tilde{r}+b)] A e^{-b t}$ and $\lim _{t \rightarrow \infty} B(t)=B^{s s}+[A /(\tilde{r}+b)]$. In addition, the weighted average time of the increase in $B$ is $1 / b$; that is,

$$
\int_{t=0}^{\infty} t \dot{B}(t) d t / \int_{t=0}^{\infty} \dot{B}(t) d t=\frac{1}{b} .
$$


Thus the policy given by (3.10) is in some sense comparable to a tax cut that causes $B$ to rise at rate $[b /(\tilde{r}+b)](A / 2)$ for length of time $2 / b$ and then remain constant at $B^{s s}+[A /(\tilde{r}+b)]$. I therefore define $\Delta T^{\prime}=[b /(\tilde{r}+b)](A / 2)$ and $H^{\prime}=2 / b$.

\subsection{THE RESPONSE OF THE ECONOMY}

The consumption of type 1 individuals at any time is equal to their disposable income:

$$
C_{1}(t)=C_{1}^{s s}+\left(\tilde{r}^{0}-\tilde{r}\right)\left(K(t)-K^{s s}\right)+\left[(\tilde{r}+b) e^{-b t}-\tilde{r}\right] \frac{A}{\tilde{r}+b} .
$$

The second term reflects the effect of the policy change on the wage and the third term the effect on taxes. (I solve for $K(t)$ below.) The consumption of type 2 individuals is constant and equal to $\tilde{r}$ times their wealth. The tax cut does not affect their financial wealth at time zero or the present value of their taxes; it does, however, affect the present value of their labor income by changing the capital stock. Thus,

$$
C_{2}(t)=C_{2}^{s s}+\tilde{r} \int_{\tau=0}^{\infty} e^{-\tilde{r} t}\left(\tilde{r}^{0}-\tilde{r}\right)\left(K(\tau)-K^{s s}\right) d \tau \quad \forall t .
$$

The dynamics of $K$ are given by

$$
\begin{aligned}
\dot{K}(t) & =Y(t)-C(t) \\
& =\tilde{r}^{0}\left(K(t)-K^{s s}\right)-\left[f\left(C_{1}(t)-C_{1}^{s s}\right)+(1-f)\left(C_{2}(t)-C_{2}^{s s}\right)\right] .
\end{aligned}
$$

The exponential path of taxes suggests a path of the capital stock of form

$$
K(t)=K^{s s}-\left(1-e^{-b t}\right) Q .
$$

It is straightforward to show that this solution satisfies (3.12)-(3.14) if $Q$ is given by

$Q=\frac{f A}{b+(1-f) \tilde{r}^{0}+f \tilde{r}}$.

$Q$ is the effect of the tax cut on the capital stock in the long run. (3.12)-(3.16) describe the impact of the tax cut on the economy.

In the absence of liquidity constraints, type 1 consumers would choose their consumption path so that $\dot{C}_{1} / C_{1}=\left(\tilde{r}-\tilde{\delta}_{1}\right) / \theta$. It follows that liquidity 
constraints are always binding on these consumers as long as $(\dot{w}-\dot{T}) /$ $(w-T)$ always exceeds $\left(\tilde{r}-\tilde{\delta}_{1}\right) / \theta$. One can show that necessary and sufficient conditions for this to occur are

$$
\frac{\frac{b+\tilde{r}^{0}}{b+(1-f) \tilde{r}^{0}+f \tilde{r}}-\frac{A}{w^{s s}-T^{s s}}}{1+\frac{b}{b+\tilde{r}} \frac{A}{w^{s s}-T^{s s}}} \leq \frac{\tilde{\delta}_{1}-\tilde{r}}{\theta}
$$

and

$1-\left[\frac{\tilde{r}^{0}-\tilde{r}}{b+(1-f) \tilde{r}^{0}+f \tilde{r}} f+\frac{\tilde{r}}{\tilde{r}+b}\right] \frac{A}{w^{s s}-T^{s s}} \geq 0$.

\subsection{WELFARE EFFECTS}

We are now in a position to describe the effect of the policy change on social welfare. As before, I proceed by first deriving analytic approximations using first order approximations to utility and then finding the exact effects numerically.

The marginal utility of consumption of type 1 individuals at time $t$ is $e^{-\tilde{\delta}_{1} t} C_{1}^{s s^{-\theta}}$. Thus, from (3.12) and (3.15)-(3.16), the effect of the policy change on the welfare of type 1 consumers is approximately

$$
\Delta U_{1} \cong C_{1}^{s^{-\theta}} \frac{b}{b+\tilde{\delta}_{1}} \frac{1}{\tilde{\delta}_{1}}\left[\frac{\tilde{\delta}_{1}-\tilde{r}}{\tilde{r}+b}-\frac{\left(\tilde{r}^{0}-\tilde{r}\right) f}{b+(1-f) \tilde{r}^{0}+f \tilde{r}}\right] A .
$$

Similarly, from (3.13) and (3.15)-(3.16),

$$
\Delta U_{2} \cong-\left(C_{2}^{s s}\right)^{-\theta} \frac{1}{\tilde{\delta}_{2}} \frac{\tilde{r}^{0}-r}{b+(1-f) \tilde{r}^{0}+f \tilde{r}} \frac{b}{b+\tilde{r}} f A .
$$

Our standard measure of the cost of the tax cut is

$$
L=-\frac{a \Delta U_{1}+(1-a) \Delta U_{2}}{\left[a\left(C_{1}^{s s}\right)^{-\theta}+(1-a)\left(C_{2}^{s s}\right)^{-\theta}\right]\left[f C_{1}^{s s}+(1-f) C_{2}^{s s}\right]},
$$


where $a$ is the weight attached to the welfare of type 1 agents. In the case of $H^{\prime}$ small, $C_{2}^{s s} \cong C_{1}^{s s}$, and $a=f,{ }^{11}$

$L \cong\left[\left(\tilde{r}^{0}-\tilde{r}\right)\left(\frac{f}{\tilde{\delta}_{1}}+\frac{1-f}{\tilde{\delta}_{2}}\right)-\frac{\theta \tilde{r}}{\tilde{\delta}_{1}} \frac{\hat{C}_{1}^{s s}-C_{1}^{s s}}{C_{1}^{s s}}\right] f H^{\prime} \frac{\Delta T^{\prime}}{C^{s s}}$.

The term in $\tilde{r}^{0}-\tilde{r}$ reflects the harms of the tax cuts through reduced capital formation while the term in $\left(\hat{C}_{1}^{s s}-C_{1}^{s s}\right) / C_{1}^{s s}$ reflects the cuts' benefits through relaxation of the liquidity constraints.

I now turn to finding exact values for $L$ numerically. As a baseline case, I consider $\tilde{r}=\tilde{\delta}_{2}=7$ percent, $\theta=3, \Delta T^{\prime} / C^{s s}=.06, H^{\prime}=10$, initial capitaloutput and bond-output ratios of 2.5 and .4 respectively, and $\delta_{1}=25$ percent; these values imply $\left(\hat{C}_{1}^{s s}-C_{1}^{s s}\right) / C_{1}^{s s} \cong .86$ (this large difference between desired and actual consumption is necessary for type 1 individuals to continue to consume their current disposable income in response to the large tax cut). If $g=3$ percent, the unadjusted discount rates, $\delta_{i}=\tilde{\delta}_{i}+(1-\theta) g$, are $\delta_{2}=3$ percent and $\delta_{1}=21$ percent. To gauge possible values of $\tilde{r}^{0}-\tilde{r}$, note that if $\tilde{r}=7$ percent, $g=3$ percent, and $\tilde{r}^{0}-\tilde{r}=30$ percent, then an initial capital-output ratio of 2.5 implies that the product of labor is zero and that all output is produced by capital. I therefore consider values for $\tilde{r}^{0}-\tilde{r}$ ranging from 0 to 30 percent; values at the upper end of the range imply very large positive externalities from capital. I also consider a wide range of values of $f$; specifically, I let $f$ range from .1 to .9 .

Table 5 presents the results. The table shows that the welfare costs are likely to be negative for $\tilde{r}^{0}-\tilde{r}$ small and positive for $\tilde{r}^{0}-\tilde{\mathrm{r}}$ large, with the magnitudes only moderate in both cases. For the case of $f=1 / 2, L$ is -.127 for $\tilde{r}^{0}-\tilde{r}=0$ (the tax cuts are advantageous in the absence of externalities), -.076 for $\tilde{r}^{0}-\tilde{r}=5$ percent, -.031 for $\tilde{r}^{0}-\tilde{r}=10$ percent, and .099 for $\tilde{r}^{0}-\tilde{r}=30$ percent. Substantial changes in $f$ do not dramatically affect the results; changing $f$ to .25 or .75 , for example, changes $L$ only moderately.

The fact that the costs of the tax cuts are only moderate when $\tilde{r}^{0}-\tilde{r}$ is large reflects a combination of large costs through a lower capital stock and large benefits through relaxation of liquidity constraints. For $f=1 / 2$ and $\tilde{r}^{0}-\tilde{r}=30$ percent, for example, the policy reduces wages by 1 percent

11. $a=f$ implies that the social welfare function puts equal weights on the instantaneous utilities at time 0 of individuals of each type (and thus, since $\tilde{\delta}_{1}>\tilde{\delta}_{2}$, smaller weight on the instantaneous utility of a type 1 than a type 2 individual at $t>0$ ). Obviously other values of $a$ are also defensible. 
after a year and 6 percent in the long run. The cost of this change to type 2 (unconstrained) consumers is roughly half a year of their consumption. But for type 1 (constrained) consumers to increase their consumption dramatically in response to the large tax cut it is necessary that they be highly liquidity constrained; thus (unless $\theta$ is small) relaxing the liquidity constraints is very desirable. The net effect (particularly since $C_{1}^{s s}<C_{2}^{s s}$, so the marginal utility of consumption for type 1 agents is greater) is only modest costs to the tax cuts. For this case $\left(f=1 / 2, \vec{r}^{0}-\tilde{r}=30\right.$ percent), the welfare cost of a deficit of 6 percent of initial consumption for ten years is about 10 percent of a year's consumption, or about 250 billion dollars - an amount that is by no means trivial, but that is dramatically less than the estimates from the model of Section 2.

One way to increase $L$ is to decrease both $\tilde{\delta}_{1}-\tilde{r}$ and $\theta$; this both makes the benefit of relaxing the liquidity constraints smaller for a given $\left(\hat{C}_{1}-C_{1}\right) / C_{1}$ and reduces the ratio of type 1's to type 2's marginal utilities. For example, $f=.5, \theta=1$, and $\tilde{\delta}_{1}=12$ percent imply $L=.102$ for $\tilde{r}^{0}-\tilde{r}=10$ percent and .350 for $\tilde{r}^{0}-\tilde{r}=30$ percent. Another way to

Table 5 THE COSTS OF EXCESSIVE DEFICITS IN THE PRESENCE OF LIQUIDITY CONSTRAINTS AND EXTERNALITIES FROM CAPITAL

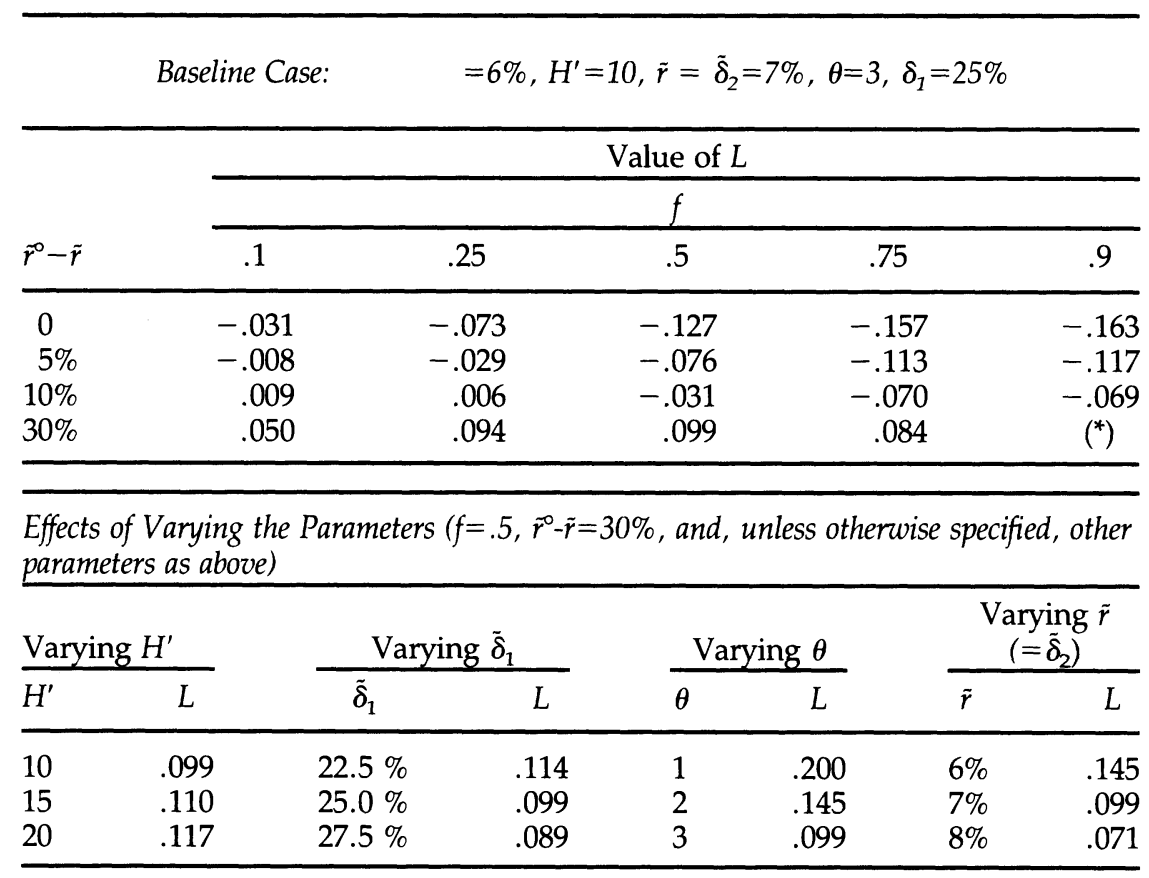

Note: $a$ is set equal to $f$ in all cases. $C_{2}^{\text {ss }}$ is found by assuming initial steady state capital-output and bond-output ratios of 2.5 and 0.4 , respectively.

(*) Condition (3.17) violated. 
increase $L$ is to reduce $\tilde{\delta}_{2}(=\tilde{r})$, so that the reduction in future consumption is more costly to type 2 agents. For example, $f=.5, \theta=3, \tilde{r}=\tilde{\delta}_{2}=4$ percent, and $\tilde{\delta}_{1}=16$ percent (implying unadjusted discount rates of $\delta_{1}=12$ percent and $\delta_{2}=0$ if $g=3$ percent) imply $L=.088$ for $\tilde{r}^{0}-\tilde{r}=10$ percent and .394 for $\tilde{r}^{0}-\tilde{r}=30$ percent.

In sum, the assumptions that deficits have large direct effects on consumption and that there are immense externalities from capital formation do not by themselves lead to large welfare costs of excessive deficits. A baseline case with large externalities yields $L \cong .1$. Selective changes of the parameter values can produce figures for $L$ as high as .3 or .4. But other, perhaps more reasonable, changes (such as assuming smaller externalities) can reduce the welfare costs considerably below .1 or even make the deficits beneficial. ${ }^{12}$

\section{Tax Smoothing}

\subsection{FRAMEWORK}

Because taxes are not lump sum, raising government revenue distorts behavior. Under standard assumptions, the cost of those distortions per unit of revenue raised is increasing in the tax rate. As a result, the distortions associated with raising a given present value of government revenue are minimized when the tax rate is constant over time. Thus, temporarily large deficits caused by a temporary tax cut cause unnecessarily large distortions in the financing of government spending.

To gauge how large this cost is likely to be, I use a simple representative agent infinite horizon model. Assume that there is a trend growth rate of the economy of $g$, let all variables be measured relative to the size of the economy, and assume that the real interest rate $r$ is fixed. As before, let $\tilde{r}$ denote $r-g$. The path of taxes, $T(t)$, must satisfy

$\int_{t=0}^{\infty} e^{-\bar{r} t} T(t)=\bar{G}$,

12. The calculations presented in this section consider policies that leave the government debt permanently higher. Some experimentation with policies of form $T(t)=$ $T^{s s}-\left[\left(\tilde{r}+b_{1}\right) A e^{-b_{1} t}-\left(\tilde{r}+b_{2}\right) e^{-b_{2} t}\right]$ (the sum of two policies of form (3.10) that together imply that $B$ returns asymptotically to its initial level) suggests that gradual repayment of the additional debt has little effect on $L$. This is the case even in the $\tilde{\delta}_{2}=\tilde{r}=4 \%$ case discussed in the text, where consumption in the relatively distant future is of considerable importance to type 2 agents. 
where $\bar{G}$ is the present discounted value of future government spending plus the value of government liabilities outstanding at time 0 .

Let $\phi(T)$ denote the "cost" of raising tax revenue of amount $T$ at a given time; specifically, let $\phi(T)$ be the size of the lump sum tax that would reduce utility by the same amount that utility is reduced by raising revenue $T$ using the actual (distortionary) instruments employed by the government. Thus, if taxes were lump sum, $\phi(T)$ would simply equal T. I assume $\phi(0)=0$, $\phi^{\prime}(T) \geqslant 1$, and $\phi^{\prime \prime}(T)>0$-raising revenue is distortionary, and the distortions increase as taxes rise. ${ }^{13}$

The government's objective should be to minimize

$$
\int_{t=0}^{\infty} e^{-\tilde{r} t} \phi(T(t)) d t
$$

subject to (4.1). The optimal policy is for $T(t)$ to be constant and equal to $\tilde{r} \tilde{G}$.

\subsection{POLICY CHANGES}

We can now analyze the cost of excessive deficits. Because there does not appear to be any widely held view that tax rates were below their steady state level before the 1981 tax cuts, I focus on the case in which the economy is initially in the optimal steady state. As before, I consider the experiment in which taxes are lowered by some amount $\Delta T$ for some length of time $H$, with taxes adjusted during this period to pay the interest on the additional debt; at time $H$ taxes are raised to keep the stock of government debt constant thereafter. The policy being considered is thus

$$
T(t)=\left\{\begin{array}{lr}
T^{s s}-\Delta T+\tilde{r} t \Delta T & 0 \leq t<H \\
T^{s s}+\tilde{r} H \Delta T & t \geq H,
\end{array}\right.
$$

where $T^{s s}$ is the initial level of taxes. Since smooth taxes are optimal, the policy after $t=H$ is the best possible one.

13. In writing the costs at $t$ as a function only of taxes at $t, \mathrm{I}$ am, following numerous authors (see, for example, Barro, 1979, and Ballard, Fullerton, Shoven, and Whalley, 1985), neglecting intertemporal effects and approximating the costs of a path of taxes by the sum of the costs when each period is treated in a static context. The fact that individuals could substitute labor supply intertemporally around the times of anticipated changes in taxes suggests that the actual costs of time-varying tax rates are somewhat larger than those computed here; the size of these additional costs would be increasing in the intertemporal labor supply elasticity. 
The effect of this policy on the utility of the representative agent, measured in time 0 dollars, is

$$
\begin{aligned}
\Delta S W= & -\int_{t=0}^{H} e^{-\tilde{r} t}\left[\phi\left(T^{s s}-\Delta T+\tilde{r} t \Delta T\right)-\phi\left(T^{s s}\right)\right] d t \\
& -\int_{t=\mathrm{H}}^{\infty} e^{-\tilde{r} t}\left[\phi\left(T^{s s}+\tilde{r} H \Delta T\right)-\phi\left(T^{s s}\right)\right] d t .
\end{aligned}
$$

Thus the welfare cost of the tax cut is $L(\Delta T)=-\Delta S W / \bar{C}$, where $\bar{C}$ is consumption at time 0 .

A Taylor expansion of $L(\Delta T)$ shows that

$$
\begin{aligned}
L(\Delta T) & \cong \frac{1}{2} \frac{\phi^{\prime \prime}\left(T^{s s}\right)(\Delta T)^{2}}{\bar{C}} \frac{1-e^{-\tilde{r} H}}{\tilde{r}} \\
& \cong \frac{1}{2} \frac{\phi^{\prime \prime}\left(T^{s s}\right)(\Delta T)^{2} H}{\bar{C}} \cdot(4.5)
\end{aligned}
$$

Since the economy begins with the optimal policy, the cost (per unit of tax cut) of a small temporary tax cut is small. The key determinant of the magnitude of (4.5), aside from the size of the tax cut, is $\phi^{\prime \prime}$. The following two illustrative calculations may be helpful in gauging plausible values of $\phi^{\prime \prime}$. First, a typical estimate of the marginal cost of additional revenue in the United States, where the ratio of tax revenue to consumption expenditures is approximately .4, is 1.4 (Ballard, Shoven, and Whalley, 1985); thus $\phi^{\prime}(.4) \cong 1.4(\bar{C}$ is normalized to 1$)$. We also know that $\phi^{\prime}(0)=1$ : the first unit of revenue can be raised without distortions. Thus the average value of $\phi^{\prime \prime}(\cdot)$ over the interval $(0,4)$ is 1 . Second, suppose that preferences are separable between consumption and leisure, that there is risk neutrality in consumption, and that labor supply has constant elasticity. Suppose also that the labor supply elasticity is chosen so that $\phi^{\prime}$ is .4 when the tax rate is .4 (roughly the average marginal rate for the United States in 1980); this implies a labor supply elasticity of .43 .14 These assumptions imply $\phi^{\prime \prime}\left(T^{s S}\right) \cong 1.96$. If we take 1 to 2 to be a plausible range of values of $\phi^{\prime \prime}\left(T^{s S}\right)$,

14. See Barro and Sahasakul (1983) and Ballard, Fullerton, Shoven, and Whalley (1985) for marginal tax rates. A labor supply elasticity of .43 is unrealistically high. This arises from my desire to obtain a realistic figure for the marginal cost of revenue using a model in which all of the distorting effects of taxation operate through labor supply. 
the welfare costs of temporary excessive deficits of 6 percent of consumption are about $.007-.16$ if $H=5$ and $.012-.026$ if $H=10$ (these calculations assume $\tilde{r}=.07$; changes in $\tilde{r}$ have little effect on the results).

Thus, the costs of excessive deficits are dramatically smaller than their costs in the models of the previous two sections. At the same time the costs do not appear trivial. $L=.02$, for example, means that the cost of the policy is 2 percent of a year's consumption-about 50 billion dollars.

\subsection{VARIATIONS ON THE BASIC POLICY}

If taxes are not adjusted during the period of the tax cut to pay the interest on the additional government debt, the path of taxes takes the form

$$
T(t)=\left\{\begin{array}{lr}
T^{s s}-\Delta T & 0<t<H \\
T^{s s}+\left(e^{\tilde{r} H}-1\right) \Delta T & t \geq H .
\end{array}\right.
$$

Analysis parallel to that used to derive (4.4)-(4.5) shows that

$$
\begin{aligned}
\hat{L}(\Delta T)= & \frac{1}{\bar{C}}\left[\frac{1-e^{-\tilde{r} H}}{\tilde{r}}\left[\phi\left(T^{s s}-\Delta T\right)-\phi\left(T^{s s}\right)\right]\right. \\
& \left.+\frac{e^{-\tilde{r} H}}{\tilde{r}}\left[\phi\left(T^{s s}+\left(e^{\tilde{r} H}-1\right) \Delta T\right)-\phi\left(T^{s s}\right)\right]\right],
\end{aligned}
$$

which can be approximated by

$$
\hat{L}(\Delta T) \cong \frac{1}{2} \frac{\phi^{\prime \prime}\left(T^{s s}\right)(\Delta T)^{2}}{\bar{C}} \frac{e^{\tilde{r} H}-1}{\tilde{r}}
$$

(4.8) exceeds (4.5) by a factor of $e^{\tilde{r} H}$. For $\tilde{r}$ and $H$ large the costs of the two policies can be quite different. Suppose, for example, $\phi^{\prime \prime}=2, \tilde{r}=.07$, and $\Delta T=.06$. Then $L$ and $\hat{L}$ respectively are approximately .015 and .022 for $H=5, .026$ and .052 for $H=10, .033$ and .096 for $H=15$, and .039 and .157 for $H=20$.

Finally, there is an asymmetry between my discussion thus far of the costs of excessive deficits through the distortionary effects of taxes and the discussion above of their costs through their impact on saving: in Sections 2 and 3 I put considerable emphasis on the possibility that the initial position of the economy was not optimal, while here I have ignored this possibility. As described above, there is a near consensus that the stock of capital in the United States has generally been inefficiently low, but no 
similar consensus that tax rates prior to 1981 were not at the level needed to smooth taxes. Nonetheless, for completeness I consider here the costs of temporary tax reductions when the path of taxes in the absence of the cut would already not be smooth.

Suppose that taxes are initially not at their optimal level of $\tilde{r} \bar{G}$, but are instead $\tilde{r} \bar{G}-\Delta T_{0}, \Delta T_{0}>0$. Since keeping the tax rate away from $\tilde{r} \bar{G}$ indefinitely would cause the stock of government debt relative to the size of the economy to diverge, for simplicity I assume that in the absence of the change in policy at $t=0$ taxes would differ from their optimal level by $\Delta T_{0}$ for some length of time $H_{0}$ and then be changed to their optimal level. Thus:

$$
T_{0}(t)=\left\{\begin{array}{lr}
\tilde{r} \bar{G}-\Delta T_{0}+\tilde{r} t \Delta T_{0} & 0 \leq t<H_{0} . \\
\tilde{r} \bar{G}+\tilde{r} H_{0} \Delta T_{0} & t \geq H_{0} .
\end{array}\right.
$$

The policy change being considered is:

$$
T(t)=\left\{\begin{array}{lr}
T_{0}(t)-\Delta T+\tilde{r} t \Delta T & 0 \leq t<H \\
T_{0}(t)+\tilde{r} H \Delta T & t \geq H .
\end{array}\right.
$$

Assuming that $H<H_{0}$, the cost of this change is:

$$
\begin{gathered}
L(\Delta T)=\left\{\int _ { t = 0 } ^ { H } e ^ { - \tilde { r } t } \left[\phi\left(\tilde{r} \tilde{G}-\left(\Delta T_{0}+\Delta T\right)+\tilde{r} t\left(\Delta T_{0}+\Delta T\right)\right)\right.\right. \\
\left.-\phi\left(\tilde{r} \bar{G}-\Delta T_{0}+\tilde{r} t \Delta T_{0}\right)\right] d t \\
+\int_{t=H}^{H_{0}} e^{-\tilde{r} t}\left[\phi\left(\tilde{r} \bar{G}+\tilde{r} H \Delta T-\Delta T_{0}+\tilde{r} t \Delta T_{0}\right)-\phi\left(\tilde{r} \bar{G}-\Delta T_{0}+\tilde{r} t \Delta T_{0}\right)\right] d t \\
\left.+\int_{t=H_{0}}^{\infty} e^{-\tilde{r} t}\left[\phi\left(\tilde{r} \bar{G}+\tilde{r}\left(H_{0} \Delta T_{0}+H \Delta T\right)\right)-\phi\left(\tilde{r} \bar{G}+\tilde{r} H_{0} \Delta T_{0}\right)\right] d t\right\} / \bar{C},
\end{gathered}
$$

which can be approximated by 


$$
\begin{aligned}
L(\Delta T) \cong & \frac{1}{2} \frac{\phi^{\prime \prime}(\tilde{r} \bar{G})}{\tilde{C}}\left[\frac{1-e^{-\tilde{r} H}}{\tilde{r}}(\Delta T)^{2}\right. \\
& \left.+2\left(\frac{1-e^{-\tilde{r} H}}{\tilde{r}}-\tilde{r} H^{2}\left(e^{-\tilde{r} H}-e^{-\tilde{r} H_{0}}\right)\right) \Delta T \Delta T_{0}\right] .
\end{aligned}
$$

Comparison of (4.12) and (4.5) shows that an approximate upper bound for the welfare costs of excessive deficits when the initial level of taxes is not optimal is $1+2\left(\Delta T_{0} / \Delta T\right)$ times the welfare costs when taxes are initially at their optimal level. For tax cuts of the magnitude that we are considering, $\Delta T_{0} / \Delta T$ is unlikely to be very large. For example, $\Delta T_{0}=.03, \Delta T=.06$ would imply that taxes (relative to consumption expenditures) were initially three percentage points below $\tilde{r} \bar{G}$ and were then cut an additional six percentage points. Yet even in this case the welfare costs of the cut would be no more than double the costs for the case of an initially optimal policy. Thus, for plausible cases, the welfare costs arising from the failure to smooth taxes are likely to be somewhat, but not dramatically, higher when taxes are initially already too low than when they are initially optimal.

\section{Conclusion}

Many economists believe that the U.S. budget deficits of recent years represent large departures from optimal policy and that the welfare costs of these departures are very high. This paper provides quantitative estimates of a variety of possible welfare costs of excessive deficits. It finds that for deficits of the size and duration experienced by the United States in the 1980 's, the welfare costs through several possible channels-crowding out caused by imperfect links between generations, a combination of liquidity contraints and externalities from capital, and departures from tax smoothing-are likely to be of moderate size. That is, the costs through these channels on the one hand certainly do not justify the dire warnings that have been made about the social costs of deficits, and on the other hand are certainly not negligible; a cost equal to roughly 10 percent of a year's consumption is typical.

But I also find that deficits may have extremely large welfare costs through a channel that is not commonly emphasized. When a conventional social welfare function is used in a model with individuals of different generations, then if the social welfare function implies that the capital stock is too low it also implies that redistributions from future to present generations lower social welfare independently of whether or not they 
affect capital accumulation. I find that for reasonable parameter values the social costs of temporarily high deficits through these distributional channels are likely to be extremely large - on the order of a year's consumption. Moreover, this is the case even if the arrival rate of new agents in the economy is extremely small. Thus, if one accepts the view that the capital stock is too low (for reasons not having to do with factor payments differing from marginal products), there is almost certainly one channel through which deficits have extremely large welfare costs.

There are a large variety of ways in which deficits could have welfare costs, and this paper has made no attempt to be comprehensive. I conclude by speculating briefly about other possible channels through which deficits might involve large costs. Specifically, I mention five possibilities.

The first two possibilities involve the model of Section 3, in which there are externalities from capital. First, as P. Romer emphasizes, in the presence of positive externalities from capital factors that affect saving can permanently change the economy's growth rate. If a period of temporary deficits could permanently reduce growth (which cannot occur in the model of Section 3), it seems likely that the welfare costs of deficits could be dramatic. Second, it is crucial to the modest net costs of deficits obtained in Section 3 that deficits have a benefit as well as a cost. If deficits have a large effect on consumption without there being a large benefit to this effect, the costs of deficits would be much larger. One possibility is that because of the difficulties of gathering and processing information about the future taxes implied by current deficits, individuals may increase their consumption in response to deficits, even though they would not do so if they were fully informed. ${ }^{15}$

A third possible reason that deficits could produce large welfare costs is that policy may be putting the economy on an explosive or unstable course. Throughout the paper I find, not surprisingly, that the costs of deficits can be much larger when they cause the stock of debt to grow exponentially rather than linearly. Moreover, an exponential path that is allowed to continue for too long may have even more dramatic consequences; see for example Tobin (1986).

Fourth, suppose that deficits cause currency appreciation and thereby harm sectors of the economy that compete with foreign producers, and that for reasons having to do with investment, marketing, or research and development a temporary advantage to foreign producers causes them to obtain a permanently greater market share. Then a period of high deficits could lead to a permanent change in the composition of output (Baldwin

15. This possibility was suggested by Lawrence Summers (who attributed it to Kenneth Arrow). 
and Krugman, 1986). It seems possible that the welfare costs through this channel could be large.

Finally, deficits could have large welfare costs through channels that are not purely economic. For example, it may be that large deficits and a high stock of government debt generate extremely harmful uncertainty about the course of government policy. ${ }^{16}$ Or large deficits and their economic effects could create political pressure for extremely undesirable policies, such as broad protectionism.

As the analysis of this paper suggests, it is virtually impossible to gauge the likely magnitude of the welfare effects of deficits through a particular channel without formal consideration of the issues involved. Thus, to obtain a clear picture of the welfare implications of large budget deficits, it is essential to analyze deficits' welfare implications through channels beyond those considered in this paper.

I would like to acknowledge financial support from Princeton's John M. Olin Program for the Study of Economic Organization and Public Policy. I thank Susanto Basu for outstanding research assistance and Laurence Ball, N. Gregory Mankiw, James Poterba, Christina Romer, and conference participants for helpful comments.

\section{REFERENCES}

Auerbach, A. J., and L. J. Kotlikoff. 1987. Dynamic fiscal policy. Cambridge: Cambridge University Press.

Baldwin, R., and P. R. Krugman. 1986. Persistent trade effects of large exchange rate shocks. NBER Working Paper No. 2017.

Ballard, C. L., D. Fullerton, J. B. Shoven, and J. Whalley. 1985. A general equilibrium model for tax policy evaluation. Chicago: University of Chicago Press.

Ballard, C. L., J. B. Shoven, and J. Whalley. 1985. General equilibrium computations of the marginal welfare costs of taxes in the United States. American Economic Review 75: 128-38.

Barro, R. J. 1974. Are government bonds net wealth? Journal of Political Economy 82: 1095-1117. $940-71$.

1979. On the determination of the public debt. Journal of Political Economy 87:

1984. Macroeconomics. New York: John Wiley and Sons.

, and C. Sahasakul. 1983. Measuring the average marginal tax rate from the individual income tax. Journal of Business 56: 419-52.

Barsky, R. B., N. G. Mankiw, and S. P. Zeldes. 1986. Ricardian consumers with Keynesian propensities. American Economic Review 76: 676-91.

Bernheim, B. D. 1987. Ricardian equivalence: An evaluation of theory and evidence. NBER Macroeconomics Annual 2: 263-304.

Blanchard, O. J. 1985. Debt, deficits, and finite horizons. Journal of Political Economy 93: $223-47$.

16. This possibility was suggested by Elhanan Helpman. 
Blumenthal, W. M., et al. 1983. Open letter to President Reagan. New York Times, January 20, p. D7.

Calvo, G. A., and M. Obstfeld. 1987. Optimal time-consistent fiscal policy with finite lifetimes: Analysis and extensions. CARESS Working Paper No. 87-109, University of Pennsylvania.

Campbell, J. Y. and N. G. Mankiw. 1987. Permanent income, current income, and consumption. NBER Working Paper No. 2436.

Feldstein, M. S. 1977. Does the United States save too little? American Economic Review 67 (May): 116-21.

Hayashi, F. 1986. Tests for liquidity constraints: A critical survey. NBER Working Paper No. 1720.

Hubbard, R. G., and K. L. Judd. 1986. Liquidity constraints, fiscal policy, and consumption. Brookings Papers on Economic Activity, no. 1, 1-50.

Johnson, S., L. Kotlikoff, and W. Samuelson. 1987. Can people compute? An experimental test of the life cycle consumption model. NBER Working Paper No. 2183.

Phelps, E. S. 1966. Golden rules of economic growth. New York: W. W. Norton.

Poterba, J. M., and L. H. Summers. 1987. Finite lifetimes and the effects of budget deficits on national saving. Journal of Monetary Economics 20: 369-91.

Roberts, P. C. 1984. The supply-side revolution. Cambridge:Harvard University Press.

Romer, P. M. 1987. Crazy explanations for the productivity slowdown. NBER Macroeconomics Annual 2: 163-202.

Tobin, J. 1986. The monetary-fiscal mix: Long-run implications. American Economic Review 76 (May): 213-18.

United States Congressional Budget Office. 1987. The economic and budget outlook: An update, August.

Weil, P. 1987a. Overlapping families of infinitely-lived agents. Harvard University Mimeo.

- 1987b. Is money net wealth? Harvard University Mimeo.

Yotsuzuka, T. 1987. Ricardian equivalence in the presence of capital market imperfections. Journal of Monetary Economics 20: 411-36.

\section{Comment}

PAUL EVANS

Ohio State University

In David Romer's view, as well as mine, the Reagan tax cut only temporarily reduced tax rates, tax rates may eventually exceed their initial levels, and the ratio of government debt to output will stabilize at a level much higher than the one that prevailed before the tax cut. If this view is correct, it would be surprising indeed if the Reagan tax cut did not result in at least some social losses. The important question is, then, how large are they? If they are small, policy makers need not be in a hurry to reduce the budget deficit and should be especially careful which tax rates are raised in order to reduce the budget deficit. In contrast, if they are large, policy makers 
should eliminate the budget deficit quickly, even if highly distorting taxes are raised in the process.

Romer estimates the social losses resulting from the Reagan tax cut in three models. One of the models is absurd, and in the other two his estimates are many times larger than I regard as reasonable. Below I provide more reasonable estimates.

The first model that Romer analyzes is Weil's modification of Blanchard's model. Because I find Blanchard's model easier to interpret, I have carried out my analysis using it rather than Weil's model. Whether one uses Weil's model or Blanchard's model does not make much difference quantitatively.

In Blanchard's model, the following two equations characterize the steady state of a closed competitive economy with a linear homogenous Cobb-Douglas technology in capital and labor measured in efficiency units:

$$
\begin{aligned}
& {\left[(1-\gamma)(1-\tau)-p(\theta-1)(1-\tau) d^{*}\right] r^{* 2}} \\
& \left.-\left[(\delta+\theta g)(1-\gamma)+\alpha g(1-\tau)+p(\theta-1)(1-\tau) \alpha+p(\delta+\theta p) d^{*}\right)\right] r^{*} \\
& +[(\delta+\theta g) \alpha g-(\delta+\theta p) \alpha p]=0
\end{aligned}
$$

and

$$
c^{*}=(1-\gamma)\left[\alpha /\left(\kappa r^{*}\right)\right]^{\alpha /(1-\alpha)}-\alpha g\left[\alpha /\left(\kappa r^{*}\right)\right]^{1 /(1-\alpha)},
$$

where $r^{*}$ is the steady-state marginal product of capital, $c^{*}$ is steady-state consumption per efficiency unit of labor, $d^{*}$ is the steady-state ratio of government debt to output, $\gamma$ is the fraction of output absorbed by the government, $\tau$ is the marginal tax rate on property income, $\delta$ is the subjective discount rate, $p$ is an index of how disconnected current members of families feel from future members, $1-\theta$ is the elasticity of the instantaneous utility function with respect to consumption, $\kappa$ is the initial capital stock per worker, $g$ is the growth rate of the effective labor force, and $\alpha$ is the share of capital in output. I have used equations (1) and (2) to calculate how the Reagan tax cut might be expected to affect the steadystate marginal product of capital and the steady-state path for consumption in Blanchard's model. I have assumed that the U.S. economy is closed; ${ }^{1}$

1. This assumption is made primarily for convenience. It turns out, however, that the total reduction in consumption is roughly the same whether the U.S. or the world is assumed to be the closed economy described by equations (1) and (2). The reason is that the percentage fall in consumption in Table 1 below is roughly linear in $d^{*}$. Therefore, if the world economy is $q$ times larger than the U.S. economy, $d^{*}$ rises by $1 / q$ times as much, the percentage fall in steady-state consumption is $1 / q$ times as much, and aggregate consumption rises by roughly $q \times(1 / q)$ times as much. 
Table 1 DESCRIPTIVE STATISTICS FOR STEADY STATES OF BLANCHARD'S MODEL

\begin{tabular}{|c|c|c|c|c|c|c|c|c|}
\hline \multirow[b]{2}{*}{$p$} & \multirow[b]{2}{*}{$\theta$} & \multirow[b]{2}{*}{$\delta$} & \multicolumn{3}{|c|}{ Marginal Product of Capital } & \multicolumn{3}{|c|}{$\begin{array}{l}\text { Percentage Fall in } \\
\text { Consumption }\end{array}$} \\
\hline & & & $d^{*}=0.6$ & $d^{*}=0.8$ & $d^{*}=1.0$ & $d^{*}=0.6$ & $d^{*}=0.8$ & $d^{*}=1.0$ \\
\hline .00 & 1 & .0400 & .1000 & .1000 & .1000 & 0.00 & 0.00 & 0.00 \\
\hline .00 & 2 & .0100 & .1000 & .1000 & .1000 & 0.00 & 0.00 & 0.00 \\
\hline .01 & 1 & .0381 & .1004 & .1006 & .1008 & 0.10 & 0.15 & 0.20 \\
\hline .01 & 2 & .0063 & .1007 & .1011 & .1015 & 0.19 & 0.30 & 0.40 \\
\hline .02 & 1 & .0357 & .1008 & .1013 & .1017 & 0.21 & 0.32 & 0.43 \\
\hline .02 & 2 & .0014 & .1017 & .1026 & .1035 & 0.43 & 0.66 & 0.89 \\
\hline
\end{tabular}

that it was in a steady state when the Reagan tax cut passed; that federal, state, and local governments always absorb 22.5 percent of output; ${ }^{2}$ that the initial ratio of capital to output is 2.5 years; that $\alpha=.25$; that the effective labor force grows 3 percent a year; ${ }^{3}$ that property income is taxed at a 30 percent marginal rate; and that the initial ratio of government debt to output is .217 years. ${ }^{4}$ Consequently, the marginal product of capital is initially 10 percent a year. Table 1 reports the new steady-state value of the marginal product of capital and the percentage amount by which the Reagan tax cut reduced the steady-state path of consumption for given values of $p, \theta$, and $d^{*} .5$

Because $p$ is found to be negative or insignificantly positive when it is estimated, using U.S. or Israeli data [Evans (1988); Leiderman and Razin (1988)], zero is the most defensible choice for $p$. For the sake of argument, however, I also consider $p=.01$ and .02. I would like to follow Romer in choosing $\theta=3$, but this value is inconsistent with $\delta>0$. I therefore consider $\theta=1$ and 2. The ratio of government debt to output is assumed to stabilize at .6, .8, or 1.0 years. Prompt tax increases could stabilize it at .6; 1.0 corresponds to substantial delay in raising taxes; and 0.8 is an intermediate case.

2. This figure is the average ratio of government purchases to net national product for 19811986.

3. I have followed Romer in choosing $\kappa=2.5$ even though I think that a larger $\kappa$ is more appropriate. My conclusions below would have been strengthened, had I chosen $\kappa>2.5$. The values for $\alpha$ and $g$ are also those chosen by Romer.

4. This figure is the ratio of the market value of the privately held federal debt [Cox (1985)] to net national income at the end of 1981III. I have measured the government debt in this way primarily for convenience. The other choices available are hardly more defensible.

5. The subjective discount rate is set so that the other parameters in the model assume the values above and the economy is initially in a steady state. I consider only values of $p$ and $\theta$ for which $\delta$ can be positive. 
Table 1 reveals that unless $p$ and $\theta$ are as large as possible and $d^{*}$ is allowed to rise beyond 1, the Reagan tax cut will not much affect the steady-state marginal product of capital ${ }^{6}$ and the steady-state consumption path. In other words, the behavior of the Blanchardian economies in Table 1 is virtually indistinguishable from the behavior of a Ricardian economy; hence Ricardian equivalence may be a good empirical benchmark.

If Blanchard's model is valid, the Reagan tax cut has produced and will produce only small changes in aggregate consumption. Romer nonetheless concludes that the tax cut resulted in enormous social losses. How can this be? The answer is that he has chosen to use a social welfare function in which future members of families are weighted heavily enough and current members of families are weighted lightly enough that these small changes in consumption produce enormous social losses. His choice of social welfare function, however, is not the only defensible one.

In Blanchard's model, each family maximizes an objective function of the form

$$
\left(\frac{1}{1-\theta}\right) \int_{0}^{\infty} e^{-(\delta+p) t}[c(t)]^{1-\theta} d t
$$

where $c(t)$ is the family's consumption in period $t$. Now, suppose that the world (or if one wants to be chauvinistic, the U.S.) ought to be one big, happy family in which current members do not feel disconnected from future members. Suppose further that the preferences of this family between present and future consumption ought to count. A social welfare function that embodies these ideals is obtained by equating $p$ to zero and replacing $c(t)$ with aggregate consumption $C(t)$ :

$$
\left(\frac{1}{1-\theta}\right) \int_{0}^{\infty} e^{-\delta}[C(t)]^{1-\theta} d t
$$

Using Blanchard's model, I have dynamically simulated the Reagan tax cut and then used the social welfare function (4) to calculate how the tax cut affected social welfare. I find that in the worst case $(p=.02, \theta=2$, and

6. Table 1 suggests that the Reagan tax cut did not appreciably affect either short-term or long-term interest rates. (This conclusion would be especially true if U.S. securities markets were well integrated into world securities markets since the effect would then be $1 / q$ times that reported in the table, where $q$ is the ratio of the U.S. capital stock to the world capital stock.) Table 1 therefore provides an explanation for why positive correlations between budget deficits and interest rates are hard to find; see, for example, Evans (1985, 1987a, 1987b, 1987c, 1987d). 
Table 2 DESCRIPTIVE STATISTICS FOR STEADY STATES OF BLANCHARD'S MODEL WITH A REDUCTION OF THE MARGINAL TAX RATE ON PROPERTY INCOME TO .25

\begin{tabular}{lccccccccc}
\hline & & & \multicolumn{3}{c}{ Marginal Product of Capital } & & \multicolumn{3}{c}{ Percentage Fall in Consumption } \\
\cline { 8 - 9 }$p$ & $\theta$ & $\delta$ & $d^{*}=0.6$ & $d^{*}=0.8$ & $d^{*}=1.0$ & & $d^{*}=0.6$ & $d^{*}=0.8$ & $d^{*}=1.0$ \\
\hline .00 & 1 & .0400 & .0933 & .0933 & .0933 & & -1.81 & -1.81 & -1.81 \\
.00 & 2 & .0100 & .0933 & .0933 & .0933 & & -1.81 & -1.81 & -1.81 \\
.01 & 1 & .0381 & .0939 & .0940 & .0942 & & -1.66 & -1.61 & -1.56 \\
.01 & 2 & .0063 & .0944 & .0948 & .0951 & & -1.51 & -1.41 & -1.31 \\
.02 & 1 & .0357 & .0945 & .0949 & .0953 & & -1.48 & -1.37 & -1.26 \\
.02 & 2 & .0014 & .0957 & .0966 & .0974 & & -1.15 & -0.92 & -0.69 \\
\hline
\end{tabular}

$\left.d^{*}=1.0\right)$ the Reagan tax cut will impose a social loss equivalent to a permanent 0.13 percent reduction in consumption beginning in 1981IV. In 1987 the reduction in consumption amounted only to $\$ 4$ billion.

Even this small figure overestimates the actual social loss if the Reagan tax cut permanently shifted taxes from capital to labor. ${ }^{7}$ Specifically, suppose that the marginal tax rate on property income fell permanently from 30 percent to 25 percent. ${ }^{8}$ Table 2 reports for several values of $p, \theta$, and $d^{*}$ the steady-state marginal product of capital and the percentage reduction in steady-state consumption resulting from the Reagan tax cut. Apparently, the effects of the reduced $\tau$ swamp the effects of the increased government debt; that is, the steady-state marginal product of capital falls and steady-state consumption rises. Clearly, then, the Reagan tax cut could have made everyone better off, and raising $\tau$ in order to reduce the budget deficit could easily make everyone worse off.

In the second model that Romer analyzes, capital is not subject to diminishing returns, no stable steady state exists, and the economy suffers an infinite social loss because it had the bad luck not to inherit an infinite capital stock. I doubt that one can learn anything useful from analyzing this model.

The third model that Romer analyzes is a tax-smoothing model. Here he derives some useful formulae, but unfortunately he plugs much too large a value for $\varphi^{\prime \prime}$ into these formulae in calculating the social losses resulting from the Reagan tax cut.

7. According to David Stockman, the Reagan tax cut was a "Trojan horse" whose purpose was to shift taxes permanently from capital to labor by first promising everyone permanently lower taxes and then eventually raising the taxes on wage income.

8. I am looking at the Reagan tax cut here from the perspective of 1981IV before TEFRA and tax reform largely eliminated the initial reduction in $\tau$. 
It is straightforward to calculate $\varphi^{\prime \prime}$ if one is willing to approximate the social loss from wage taxation as the area between the labor demand and supply curves. If competition prevails, if output is produced with a Cobb-Douglas technology, and if the compensated elasticity of labor supply is the constant parameter $\epsilon$, then the social loss resulting from wage taxation at the marginal rate $\mu$ is

$$
\begin{aligned}
& \frac{1}{1+\varepsilon}+\left(\frac{\varepsilon}{1+\varepsilon}\right)[(1-\alpha)(1-\mu)]^{(1+\varepsilon) /(1+\alpha \varepsilon)} \\
& -[(1-\alpha)(1-\mu)]^{\varepsilon(1-\alpha) /(1+\alpha \varepsilon)},
\end{aligned}
$$

where $1-\alpha$ is the share of labor in output. This social loss is measured relative to the wage bill that would prevail, were $\mu$ zero. Calculating $\varphi^{\prime \prime}$ is then simply a matter of differentiating (5) twice with respect to $\mu$ and evaluating the resulting expression at appropriate values of $\alpha, \mu$, and $\epsilon$. Following Romer, I assume that $\alpha=.25$ and $\mu=.4$. According to Ballard, Shoven, and Walley (1985), a reasonable estimate of the compensated elasticity of aggregate labor supply is .15. Therefore, $\varphi^{\prime \prime}=.47$, and the social loss resulting from the Reagan tax cut is equivalent to a one-time loss of $\$ 10$ to $\$ 20$ billion. For $\varphi^{\prime \prime}$ to be in the range 1 to 4 that Romer chooses would require that $\epsilon$ be appreciably larger than .4. Virtually the only economist who thinks the aggregate labor supply is that elastic is Art Laffer!

I conclude that David Romer has not made a convincing case that the Reagan tax cut produced large social losses.

I thank Steve Cecchetti for helpful comments.

\section{REFERENCES}

Ballard, C. L., J. B. Shoven, and J. Whalley. 1985. General equilibrium computations of the marginal welfare costs of taxes in the United States. American Economic Review 75: 128-38.

Cox, M. 1985. The behavior of treasury securities: Monthly, 1942-1984. Journal of Monetary Economics 16: 227-50.

Evans, P. 1985. Do large deficits produce high interest rates? American Economic Review 75: 34-58.

- 1987a. Interest rates and expected future budget deficits in the United States. Journal of Political Economy 95: 34-58.

- 1987b. Do budget deficits raise nominal interest rates? Evidence from six countries. Journal of Monetary Economics 20: 281-300.

- 1987c. Are government bonds net wealth? Evidence for the United States. Forthcoming in Economic Inquiry. Inquiry.

Leiderman, L., and A. Razin. 1988. Testing Ricardian neutrality with an intertemporal stochastic model. Journal of Money, Credit, and Banking 20: 1-21. 


\section{Comment}

JAMES TOBIN

Yale University

Reagan fiscal policies raised the ratio of federal debt to GNP by about 15 percentage points in five years, reversing a downward trend in the ratio ever since 1946. The deficits of the 1980s, 4 percent to 5 percent of GNP, even in fair economic weather, were a new departure. So were the high real interest rates that accompanied them, even after victory over inflation had been declared. The "real world" we economists purport to study seldom performs for us so dramatic an experiment. Analysis and measurement of its effects present an opportunity and a challenge to macroeconomics. The profession's response has been divided and uncertain.

David Romer's paper was invited, I guess, in order to bring some order and precision into the debate by examining and estimating the various alleged costs of a period of deficit spending. Romer does not assess the effects econometrically, although his work might be a prelude to such attempts. Instead, Romer deploys state-of-the-art theory and tries to pin down quantitative orders of magnitude by plausible simulations.

Romer has executed his commission very well—at least he will have after another iteration. Good papers generally contain some surprises. Here the surprise is the high estimate of welfare costs attributable to deficits' transfer of wealth from future citizens to the present generation. These costs are high, in particular, relative to the modest costs of "crowding-out." Romer does find crowding-out to be substantial when households are liquidityconstrained, but the welfare costs are roughly offset by the welfare gains from relaxation of those constraints. With liquidity constraints there is over-saving; some workers are not able to consume now as much of the wealth represented by their future wages as they would like.

Good papers also stimulate further work, and Romer's will surely do that. The art of economics is rarely in a state where it is fully ready to be applied to important practical problems. Our tools are invented and honed by being used. That is the opportunity afforded by Reagan fiscal policy.

\section{Crowding Out}

Those economists who, like myself, deplored the drastic departure from pre-Reagan policies, did so for two reasons.

First, we saw that the new policy mix was putting the budget and the economy on an unstable track, along which the debt/GNP ratio would 
grow explosively. This was a warning, not a prediction. The prediction was that policies which were so clearly recipes for instability would be changed sooner or later. This has happened. Congress cut short the President's defense buildup, restored bits and pieces of tax revenue, agreed with the President on a compromise program to keep social security solvent, and twice enacted Gramm-Rudman targets for deficit reduction. Thus David Romer notes that his study of the costs of the Reagan fiscal experiment is not a story of catastrophic reckoning, but a more mundane calculation of the costs of temporary and finite fiscal and social profligacy.

There is a technical analytical difficulty here. An unstable rise in the debt/ GNP ratio results when the outstanding debt is positive, the real interest rate on it exceeds or equals the economy's growth rate, and the primary budget (i.e. excluding debt service) is in deficit. According to Phelps's golden rule criterion of efficiency, the net marginal productivity of capital should not be less than the growth rate. This condition seems to guarantee that any deficit spending policy will be unstable. A resolution of the problem is that the interest rate relevant to the Treasury can be smaller than the growth rate, even if the marginal productivity of capital is not. The Treasury taxes debt interest along with other income, whereas it is the pre-tax return to capital that is relevant to the Phelps condition. Public debt is less risky and bears a lower interest rate than privately owned capital. Part of the public debt is monetized, so that the public benefits from seignorage. Romer dodges explosive scenarios by assuming that taxes are adjusted to pay interest as debt rises.

Second, we economists objected to the fiscal policies of the 1980s on the old-fashioned classical and Keynesian grounds of "crowding-out." We assumed that Barro-Ricardo neutrality does not hold. Anyway, it doesn't make sense to tell politicians and voters they need do nothing about deficits because taxpayers will behave on the expectation that they will do something some day. We assumed that a new and higher debt/GNP ratio would be maintained and not rolled back, and that the aggregate demand impacts of fiscal policies would be wholly offset by monetary policies or market prices. The crowding-out cost calculation would concern the effects of a cut of 0.15 in the capital/GNP ratio, equal to the rise in the debt/GNP ratio.

The comparative statics of steady states are not very exciting. I used essentially the same assumptions as Romer. In Section 2.3 he makes Net National Product a Cobb-Douglas function of capital and labor, with elasticities of 0.25 and 0.75 . (Readers should be careful not to confuse this Romer model of production with the linear CRS model he uses elsewhere. That model, which assumes that labor and capital are perfect substitutes, surely distorts and biases the results for the significant finite variations in which we are interested.) I prefer to take the production function to apply 
to Gross National Product and to subtract capital depreciation explicitly. To make this change and at the same time retain Romer's calibration of the net marginal product of capital at 0.10 , I have to make the elasticities of output 0.33 for capital and 0.67 for labor.

Romer assumes an initial capital/NNP ratio of 2.5. Assuming a depreciation rate of 0.05 , the corresponding capital/GNP ratio is 2.22 . It is this that I assume Reagan lowered to 2.07. The public's desired wealth/GNP ratio is thus assumed not to respond either to the interest rate, which rises by 100 basis points, or to the prospect of higher future taxes. In a steady state K, GNP, NNP, and other real aggregates grow at 3.0 percent per year, of which 2.0 is labor-augmenting progress and 1.0 is labor force growth. These are Romer's numbers. Along the reference track, the gross investment required is 17.8 percent of GNP; along the new path it is 16.6 percent. The rest is available for "consumption," private and public. (By the way, Romer ignores the existence of government purchases " $\mathrm{G}$ ", which amount to 21 percent of GNP, and so will I. I do note that even if this is all assumed to be consumption, it takes the form of public goods equally available to citizens of all co-existing generations.) Per capita consumption along the "post-Reagan" steady-state path is 98 percent of that of the reference track. The welfare loss is even smaller, of course, because the transition is slow and initially provides increases in consumption.

Losing 2 percent of consumption is like setting the growth calendar back one or two years. William Fellner used the same metric to minimize the cost of raising the unemployment target by a point. Surely, he told me, it is worth it to lower the risk of being on the wrong side of the inflation-safe threshold. The politics of government spending and taxing waxes passionate about even smaller amounts. Temporary and finite profligacies are not going to look big sub specie aeternitatis.

However, the concerns we economists voice about "crowding out" seem disproportionate to the Cobb-Douglas growth-theoretic calculations of Romer and myself, which are of course nothing new. Probably we suspect those calculations understate the effects. As a veteran of past heydays of growth and capital theory, I suggest some reasons. Cobb-Douglas probably overstates the possibilities of substituting labor for capital. More important, models in which technical progress is embodied in successive vintages of investment goods would attribute greater importance to investment, even replacement investment. The age of capital in use may be a better index of capital intensity than the ratios of undepreciated stock to labor or output. Learning by doing can be the source of an externality that magnifies the contribution of investment to productivity growth. Perhaps we should allow capital-augmenting as well as labor-augmenting progress (in production specifications, not Cobb-Douglas, where the distinction is meaning- 
ful). This would sacrifice steady state equilibrium, while making the growth rate itself endogenous. Finally, we are probably being too narrow in our conception of "K." We know better, but we tailor our calculations and simulations to identify capital with durable business plant and equipment, homogeneous over time and space. Yet there are also public capital and human capital, in both of which vintage effects and embodied progress could be important.

\section{Liquidity Constraints}

In the model of Romer's Section 3, deficits crowd out investment because tax reductions enable current liquidity-constrained consumers to spend more. The government, in effect, borrows on their behalf from the affluent future. In welfare calculus, the gains of relaxing constraints that reflect imperfection or incompleteness of capital markets compensate for most of the costs of crowding-out. The relevance of this model to the events and policies that triggered the paper is pretty thin. The deficits of the 1980s did not come from tax cuts and transfers designed to help the segments of the population most likely to be liquidity-constrained. Generalized fiscal deficits do not look like good remedies for liquidity constraints. However, there may well be a case for expanding the role of the federal government as a financial intermediary, especially for young people investing in education.

\section{Tax-Smoothing}

Romer finds no big deal in conventional crowding-out. He discusses two other sources of costs of deficits. One comes last in his paper, in Section 4: Like Robert Barro, Romer detects social costs in changing taxes from year to year, even when the changes are correctly foreseen. Tax-smoothing minimizes the sum of discounted future deadweight losses, subject to the constraint that the discounted sum of tax collections meet the prescribed need for revenue. The loss at each time is taken to be simply an increasing function of contemporaneous revenue, with an increasing first derivative. But we know very little about the underlying technology of deadweight losses. Surely there are complicated interactions between periods. Can we even be sure that marginal costs in any one period are increasing? Is it obvious that ten years of 25 percent tax rates are less distortionary than five years of 50 percent rates and five of zero rates? In any case, Romer does not estimate significant costs from the temporary tax cuts he simulates. Moreover, we don't know whether the 1981 tax cuts are anti-smoothing or pro-smoothing; maybe Reagan will have won his battle against the public sector and his new lower taxes will be permanent. 


\section{Intergenerational Redistribution}

Romer's most striking finding - surprising at first glance, but intuitive once you understand it-is the substantial welfare cost of perverse redistribution from the unborn to the living. That is the wrong direction if the interest rate is above its optimum, according to the modified golden rule. In that situation future generations are already being shortchanged: the capital stock is too small. Tax cuts enabling living taxpayers to add further to their lifetime consumption at the expense of future taxpayers just compound the felony. This is true even if the deficits are not charged with any further crowding-out. Indeed, the redistribution costs are first order, while the crowding-out effects are second order and, as already noted, small.

How do we know the U.S. was under-capitalized in 1980? Romer just cites the widespread opinion, within and beyond the profession, that the country chronically saves too little. His calculations assume that the optimal real interest rate is 6 percent, the product of an elasticity of marginal utility (his $\theta$ ) equal to 3 , and labor-augmenting progress $g$ of 2 percent per year. (It would be 7 percent, including 1 point for population growth, if the social welfare judge valued the per capita consumption utility of each generation unweighted by the size of the generation. But if $\theta$ were less than or equal to 1 , the optimal interest rate would be below the Phelps efficiency threshold, $n+g=0.03$, making public debt rather than capital the preferred vehicle of intergenerational transfers.) Romer assumes that the net marginal productivity of capital is 10 percent. Following a long and noble tradition in welfare economics, intergenerational neutrality, Romer takes the social time preference discount rate $\beta$ to be zero. But $\delta$, the personal time preference rate of consumers of all generations, is not zero. In his baseline case it is 3.3 percent; it has to be in order to generate saving consistent with the chosen parameters and with realistic initial values of capital/output and debt/output ratios. The difference between the withingeneration discount $\delta$ and the across-generation discount $\beta$ is the source of the under-capitalization.

While I agree qualitatively with the result, I do not think the BlanchardWeil model Romer used for quantitative simulation was a happy choice. In the model, everyone lives forever, but discounts the future as if he did not expect to (or she? - as far as I can see there is just one sex, thus no sex, in this world.) Some start their infinite lives later than others. But, looking forward from today, we were all just born (that is, just newly arrived adults), except that oldtimers are starting with some accumulations of savings. (It seems hard to specify a convergent social welfare integral over generations from minus infinity to plus infinity. See equations 2.20 and 
$2.20^{\prime}$, which are bound to diverge in one direction or the other, depending on the sign of $\beta-n$.)

With this demography and biology, it is hard for me to see why a rational person's $\delta$ should be nonzero. If I nevertheless swallow the positive $\delta$, it is hard to see why I should make $\beta$ differ from it. If people lived forever, would they need government to protect the society's future? If students and faculties lived on campus forever, would we need trustees to assure the immortality of the university?

Note that in this model positive saving occurs only if $r$ exceeds $\delta$. If that condition is met, no one will ever want to dissave; and no one will ever be liquidity-constrained. With no life cycle or retirement saving, and with no age preferences, there is nothing to give rise to variations over time in individual saving rates. Nor are there generational vintage effects on labor quality and productivity, such as those so evident in conferences like this.

In the literature that Romer's paper is bound to provoke, I hope life cycle models more faithful to human biology and demography will replace the Blanchard-Weil-Romer model. Life cycle models do not need to assume away all intergenerational bonds. And liquidity-constraints can arise naturally in them from realistic age-earnings profiles and do not have to be introduced as dei ex machinae.

I allow myself a concluding obiter dictum. When I was a boy, interpersonal cardinal utility comparisons were considered a "no-no." Now they are unapologetically and routinely used to evaluate intergenerational equity and social welfare, usually in models where each generation is represented by a single typical agent. The same comparisons can of course be used to evaluate other inequalities and redistributions, given that agents have widely different endowments. Maybe within-generation inequities and welfare losses are greater than those between generations. For example, Abba Lerner was bold enough to ignore the above taboo and to use declining marginal utility as a justification for progressive taxes and transfers. Maybe the future is being shortchanged, but we should be cautious in seeking remedies that would increase contemporaneous inequalities of income and wealth in order to increase saving and investment for the benefit of future consumers, most of whom will be better off than most Americans today.

\section{Discussion}

Several people chose to focus on factors which are not addressed in Romer's analysis. Olivier Blanchard pointed out that Romer's calculations 
ignore the benefits from learning by doing and running a deficit during a recession. Paul Evans and Larry Kotlikoff argued that the method of taxation by which a given deficit is reduced can be quite important. While Paul Romer asserted that the key question is whether deficits-through their impact on savings - affect growth rates. If growth rates are adversely affected then costs of deficits could be quite high. Larry Summers worried that open economy implications, particularly the possible instabilities for certain sectors of the economy, were overlooked.

With respect to the models in the paper, particularly that of section 2, David Romer agreed that the choice of social welfare function was critical but felt that using one that did not separately weigh the utility of generations would be misleading. For instance, maximizing aggregate consumption may lead to inefficient equilibria. He also reiterated that the labor supply elasticity assumed in the tax smoothing model was required to fit the stylized facts. Andrew Abel pointed out that the costs of the deficit depend on the spread between $r$ and $r^{*}$ and empirically its not clear how to measure $r$, different proxies can lead to different conclusions. The result in the paper is achieved by means of a high $r$, but this could also be achieved by a low $\beta$. Maurice Obstfeld added that the use of a constant interest rate assumption is not innocuous.

Finally Robert Hall argued that the assumption that taxes will definitely be increased is dubious. He argued instead that government spending was likely to be adjusted and that deficit may stabilize without a further increase in taxes. James Tobin noted that cutbacks in government spending may not be desirable and that justifying the deficit now as being needed to fight the 1982 recession is inappropriate, since monetary policy might have been used instead. 